\title{
BİTKİSEL KAYNAKLI ANTI-HIV BİLEŞİKLER \\ PLANT ORIGINATED ANTI-HIV COMPOUNDS
}

\section{Belma KONUKLUGIL}

\section{Özlem BAHADIR}

\author{
Ankara Üniversitesi, Eczacılık Fakültesi, Farmakognozi Anabilim Dalı, \\ 06100 Tandoğan ANKARA-TÜRKIYE
}

\section{ÖZET}

AIDS 1980'li yıllardan beri bilinen, immün sistemin baskılanmasıyla ortaya çıkan bir viral hastalık olup HIV(Human İmmunodeficiency Virüs), bu hastalı̆̆a neden olan başlıca etken olarak tanımlanmıştır.

Doğal ve sentetik birçok bileşiğin anti-HIV aktivitesi saptanmasına rağmen; bunlardan çok azı klinik kullanım aşamasına ulaşmıştır. Anti-HIV aktivite gösteren bileşiklerin ar aştırılmasındaki yaklaşımlardan biri de tıbbi bitkilerin bu konuda değerlendirilmesidir.Bitkisel kaynaklardan izole edilen çok sayıda bileşiğin anti-HIV aktivite gösterdiği tespit edilmiştir.

Bu derlemede çeşitli bitkisel kaynaklardan izole edilmiş, anti-HIV aktivite gösteren doğal bileşikler tanımlanmaktadır.

Anahtar Kelimeler: Anti-HIV aktivite, AIDS

\begin{abstract}
AIDS (Acauired Immune Deficiency Syndrome) that has been known since 1980's, is a pandemic immunosupressive disease and HIV (Human Immunadeficiency Virüs) is identifled as the primary cause of this disease.

Although, several natural and synthetic compounds were detected to possess anti-HIV activity, only a few of them are licensed for clinical use. One of the approaches on the investigation of the compounds with anti-HIV activity is to investigate the medicinal plants. Numerous compounds isolated from plant sources were shown to possess anti-HIV activity.

The current review describes the anti-HIV active natural compounds isolated from various plant sources

Key Words: Anti-HIV activity; AİDS
\end{abstract}




\section{GİRIŞ}

HIV (Human Immunodeficiency Virüs) AİDS'e neden olan bir RNA virüsüdür. Bu virüs insan organizmasında, CD4 reseptörü taşıyan lenfosit, monosit ve makrofajlara ilgi göstermektedir. (1), (2)

CD4 reseptörü taşıyan bu hücreler, organizmanın immün yanıt mekanizmasının düzenli bir şekilde yürütülmesini sağlarlar. HIV ile enfekte olan hücreler, hem kendi protein sentezlerini yapamadıklarından çoğalamamakta, hem immün yanıt mekanizmasındaki görevlerini yerine getirememekte ve hem de virüsün meydana getirdiği sitopatik etkiler nedeniyle sayıları azalmaktadır. $\mathrm{Bu}$ hücrelerin sayısındaki azalmanın sinsitiya oluşumu denilen bir olayla desteklendiği savunulmaktadır. Sinsitiya oluşumunda gp120 adı verilen, virüs yüzeyinde bulunan ve virüsün konakçı hücrelere tutunmasını sağlayan glukoprotein yapıları önemli rol oynamaktadır. Virüs ile enfekte olan bir hücrede, yeni üretilen gpl20'ler hücre zarına yerleşmektedir. $\mathrm{Bu}$ glukoproteinlerin $\mathrm{CD} 4$ reseptörüne olan ilgisinden dolayı bu reseptörü taşıyan sağlıklı lenfositlere yapışır. Böylece virüs bulaşmış olan hücre, etrafındaki diğer sağlıklı hücreleri yapıştırarak büyük bir yığın, dev bir hücre meydana getirir. Bu şekilde lenfositlerin tükenmesine neden olan bu mekanizmaya sinsitiya formasyonu adı verilir.

Sonuçta immün sistem fonksiyonları zayıflamaya başlamakta ve hatta zamanla tümüyle kaybolmaktadır. İmmün sistemi zayıflamış veya tümüyle tükenmiş bir organizmanın enfeksiyonlara ve malign hastalıklara yakalanma riski artmaktadır. AİDS hastalarındaki ölümler bu malign hastalıklar ve enfeksiyonlar nedeniyle olmaktadır. (1), (2), (3)

HIV'in konakçı hücrelerdeki yaşam siklusu şu şekildedir:

1. Virüsün konakçı hücreye adsorbsiyonu: Virüs kendi yüzeyinde bulunan, gp120 adı verilen glukoprotein yapısındaki çıkıntılar vasıtasıyla, konakçı hücre yüzeyindeki CD4 reseptörlerine bağlanır.

2. Virüs-hücre birleşmesi

3. Revers Transkripsiyon: Konakçı hücrenin sitoplazmasına bırakılan virüse ait nükleokapsit içinde virüs genomu ve virüs için gerekli enzimler bulunmaktadır. $\mathrm{Bu}$ aşamada, HIV RNA'sından, revers transkriptaz enzimi yardımıyla DNA sentezlenir.

4. İntegrasyon: İntegraz enzimi yardımıyla, virüs DNA'sı konakçı hücre genomuna entegre edilir. 
5. Protein sentezi: Virüse ait proteinler sentezlenmeye başlar.

6. Tomurcuklanma ve Salıverilme: Konakçı hücre içinde oluşan yeni virionlar tomurcuklanma yoluyla hücre dışına çıkıp yeni hücreleri enfekte ederler.

HIV replikasyon siklusunda büyük önem taşıyan bir diğer enzim de proteaz enzimidir. Bu enzim, çeşitli protein zincirlerinin yarılmasını sağlamak suretiyle enfeksiyon yapabilme yeteneğine sahip HIV partiküllerinin oluşumunda çok büyük bir rol oynamaktadır. (3), (4)

AİDS tedavisinde kullanılan, HIV üzerine etkili ilaçlar, virüs için çok gerekli olan bu 3 enzimi (revers transkriptaz, proteaz, integraz) ve replikasyon siklusunun tüm basamaklarını etkileyebilir.

Bugün piyasada bulunan ve klinik kullanımda olan ilaçlar, revers transkriptaz ve proteaz inhibitörleri şeklindedir. (3)

Günümüze kadar uygulanmış ve halen uygulanmakta olan tedavi yöntemleri ve ilaçların hiçbirisi ile virüsün organizmadan tamamen arındırılması söz konusu değildir. Uygulanan tüm tedavi yöntemleri hastanın yaşam süresini ve yaşam koşullarını iyileştirmeye yöneliktir. (3)

AİDS tedavisinde kullanılabilecek yeni etkili bileşikler için araştırmalar büyük bir hızla devam etmektedir. Araştırmaların yoğunlaştığı alanlardan bir tanesi de bitkisel kaynaklardır. Yapılan çalışmaların sonuçlarına göre bitkisel kaynaklardan izole edilen çok sayıda bileşik HIV replikasyon siklusunun farklı basamaklarında ve HIV enzimlerine karşı inhibitör etkiye sahiptirler.

Bitkisel kaynaklardan izole edilen bu tip bileşiklerden in vitro ortamda belirgin bir inhibitör etki gösterenler, klinik çalışmalara tabi tutulmuştur. $\mathrm{Bu}$ bileşiklerden bazılarının in vitro ortamda belirgin bir inhibitör etkiye sahip olmalarına karşın, klinik çalışmalarda beklenen etkinin gözlenmemesi yada şiddetli yan etkiler göstermeleri nedeniyle bu bileşikler üzerindeki çalışmalara son verilmiştir. Bazı bileşikler ile yapılan klinik çalışmalarda ise oldukça umut verici sonuçlar alınmıştır. (4)

Bitki ekstreleri ile yapılan çalışmaların bir kısmında ise anti-HIV aktivite gözlenmiş fakat etkili olan maddeler izole edilememiştir

In vitro ortamda yapılan deneyler sonucunda etkili bulunan bileşikler, dahil oldukları etken madde gruplarına göre düzenlenmiş, izole edildikleri bitkisel kaynaklar ve etki şekilleri ile beraber Tablo I de verilmiştir. 
Tablo I: H1V üzerine etkili olan bileşikler, elde edildikleri bitkiler ve etki şekilleri

Bitki adı ve

Etkili Bileşik

Etki Şekli

Kullanılan Kısmı

ALKALOİTLER:

Alexa leiopetale

Kastanospermin (1)

(Leguminosae) Meyva

Buchenavia capitata

O-demetilbukenaviyanin (2)

(Combretaceae) Yaprak

Castanospermum australe

Kastanospermin (1)

(Leguminosae) Tohum

Cephaelis ipecacuanha

(Rubiaceae) Kök ve rizom

\section{Euodia roxburghiana}

Ometilpsikotrin

sülfat heptahidrat (3)

Psikotrin dihidrojen-

okzalat (4)

Bukapin (5)

(Rutaceae) Çiçek, yaprak

ve sürgünler

\section{Litneria floridana}

(Letneriaceae)

\section{Toprak üstü}

Omphalea diandra

(Euphorbiaceae) +

\section{Schumanniophyton}

Şumannifisin (9)

magnificum (Rubiaceae)

1-metoksikantinon

3-(-metil-2-bütenil)-4-((3metil-2-bütenil)oksi)-

2-(1H)kinolinon (6)

1-deoksinojirimisin
Virionlarm konakçı hücrelere bağlanma ve sinsitiya formasyonu inhibitörü (4), (5)

HIV'in sitopatik etkilerine karşı koruma ( $\left.\mathrm{EC}_{50}=0,26 \mathrm{uM}\right)(6)$ Virionlarm konakçı hücrelere bağlanma ve sinsitiya formasyonu inhibitörü (4), (5)

HIV-1-RT inhibitörü

$\left(\mathrm{IC}_{50}=21,8 \mathrm{ug} / \mathrm{ml}\right)(7)$

HIV-l-RT inhibitörü

$\left(\mathrm{IC}_{5} \mathrm{O}=18,3 \mathrm{u} . \mathrm{g} / \mathrm{ml}\right)(7)$

HIV-l'in sitopatik etkilerine karşı koruma $\left(\mathrm{EC}_{50}=0,94^{\wedge} \mathrm{M}\right)$

HIV-1-RT inhibitörü

$\left(\mathrm{IC}_{50}=12 \mathrm{uM}\right)(8)$

HIV'in sitopatik etkilerine karşı koruma $\left(\mathrm{EC}_{50}=1,64 \mathrm{uM}\right)$

HIV-1-RT inhibitörü

$\left(\mathrm{IC}_{50}=8 \mathrm{uM}\right)(8)$

HIV replikasyon inhibitörü

$\left(\mathrm{EC}_{50}=0,256 \mathrm{u} \cdot \mathrm{g} / \mathrm{ml}\right)(9)$

Virionlarm konakçı hücrelere bağlanma ve sinsitiya formasyonu inhibitörü (4), (10) gpl20 ile irreversibl olarak etkileşir (4) 


\section{Kök kabukları}

Stephania cepharantha

eder

(Menispermaceae) Kök

FK-3000 (11)

Toddalia asiatica

(Rutaceae) Kök

Tripterygium hypoglaucum

(Celastraceae)

Kök kabukları

(Lamiaceae) Yaprak

Euphorbia myrisinites

(Euphorbiaceae)

\section{Homoalanthus nutans}

(Euphorbiaceae)

\section{Gövde kabukları}

Tripterygium wilfordii

(Celastraceae) Kök

\section{Xylopia sp.}

(Annonaceae) Meyva

Nitidin (12)

Hiponin B(14)

Vilfortrin(16)
Aromolin (10)

HIV'in sitopatik etkilerini inhibe

$\left(\mathrm{IC}_{\mathrm{IoO}}=31,3 \mathrm{ng} / \mathrm{ml}\right)(11)$

HIV'in sitopatik etkilerini inhibe eder

$\left(\mathrm{IC}_{10} \mathrm{O}=7,8 \mathrm{ug} / \mathrm{ml}\right)(11)$

HIV-1-RT inhibitörü

$\left(\mathrm{EC}_{50}=1,4 \mathrm{uM}\right)(12)$

Triptonin B (13)

HIV replikasyon inhibitörü

$\left(\mathrm{EC}_{50}=<0, \operatorname{lug} / \mathrm{ml}\right)(13)$

HIV replikasyon inhibitörü

$\left(\mathrm{EC}_{50}=0,1 \mathrm{ig} / \mathrm{ml}\right)(13)$

Hipoglaunin B(15)

HIV replikasyon inhibitörü

$\left(\mathrm{EC}_{5} \mathrm{O}=0, \operatorname{lug} / \mathrm{ml}\right)(13)$

HIV replikasyon inihibitörü

$\left(\mathrm{EC}_{50}=<0,10 \mid \mathrm{ag} / \mathrm{ml}\right)(13)$

HIV'in konakçı hücrelere

Dehidroandrografolit

süksinik asit monoester (17)

Ovatodiolit (18)

15-O-asetil-3-0-butanol-

5-0-propionil-7-0-

nikotinoilmirsinol (19)

15- O-aseti 1-3,5-0-dibutanol

7-O-nikotinoilmirsinol (20)

Prostratin (21)

Tripterifordin (22)

Ksilopinik asit (23)

bağlanma ve sinsitiya formasyonu inhibitörü

$\left(\mathrm{EC}_{50}=1,6-3, \mathrm{lu} . \mathrm{g} / \mathrm{ml}\right)(14),(15)$

HIV-1'in sitopatik etkilerini inhibe eder $(\mathrm{EC} 50=0,10 \mathrm{ug} / \mathrm{ml})(16)$

HIV-1-RT inhibitörü

$\left(\mathrm{IC}_{50}=80 \mathrm{ng} / \mathrm{ml}\right)(17)$

HIV-1-RT inhibitörü

$\left(\mathrm{IC}_{5} \mathrm{O}=67 \mathrm{u} . \mathrm{g} / \mathrm{ml}\right)(17)$

HIV'in sitopatik etkilerine

karşı koruma sağlar

$\left(\mathrm{EC}_{50}=<0,132 \mathrm{uM}\right)(12)$

HIV replikasyon inhibitörü

$\left(\mathrm{EC}_{50}=\mathbf{l p g} / \mathrm{ml}\right)(18)$

HIV'in sitopatik etkilerine

karşı koruma sağlar

$\left(\mathrm{EC}_{50}=0,9 \mid \mathrm{aM}\right)(7)$ 
FENOLİK BİLEŞİKLER

Arnebia euchroma

(Boraginaceae) Kök

Cordia spinescens

(Boraginaceae) Yaprak

Curcuma longa

(Zingiberaceae) Rizom

Lithospermum erythrorizon

(Boraginaceae)

FLAVANOİTLER :

Acer okamotoanum

(Aceraceae) Yaprak

Chamaesyce hyssopifolia

(Euphorbiaceae)

\section{Kafeik asit}

monosodyum tuzu (24)

Kafeik asit

monopotasyum tuzu (25)

İzomerik kafeik asit

monosodyum tuzu (26)

Magnezyum litospermat (27)

Kalsiyum rozmarinat (28)

Magnezyum rozmarinat (29)

Kurkumin (30)

Litospermik asit tuzlan

Kersetol-3-0-(2", 6"-0-digallol) HIV-1-integraz inhibitörü

-P-D-galaktopiranozit (31)

Kersetol-3-0-(2"-gallol)

-a -L-arabinopiranozit (32)

Kersetol 3-0-(2"-gallol)

-P -D-galaktopiranozit (33)

Gallik asit metil esteri (34)

1,2,6-tri-O-gallol-P-D-glukoz

1,2,3,4,6-penta-O-gallol-P-Dglukoz (36)

Kersetol-3-O-P-D-

glukopiranozit (37)
HIV replikasyon inhibitörü

$\left(\mathrm{EC}_{50}=2,8 \mathrm{iig} / \mathrm{ml}\right)(19)$

HIV replikasyon inhibitörü

$\left(\mathrm{EC}_{50}=4 \mathrm{ng} / \mathrm{ml}\right)(19)$

HIV replikasyon inhibitörü

$\left(\mathrm{EC}_{50}=1,5 \mathrm{jig} / \mathrm{ml}\right)(19)$

HIV- 1-RT inhibitörü

$\left(\mathrm{IC} \gg=0,8^{\wedge} \mathrm{iM}\right)(20)$

HIV-1-RT inhibitörü

(İÇ* $=5,8 \mathrm{pM})(20)$

HIV-1-RT inhibitörü

$\left(\mathrm{IC}_{5} \mathrm{O}=3,1 \mathrm{MM}\right)(20)$

HIV replikasyon inhibitörü

HIV integraz inhibitörü

(21), (22)

HIV replikasyon inhibitörü

$\left(\mathrm{IC}_{50}=18, \operatorname{lng} / \mathrm{ml}\right)(23)$

HIV-1-integraz inhibitörü

(İÇ» $\left.=24,2^{\wedge} \mathrm{g} / \mathrm{ml}\right)(23)$

HIV-1-integraz inhibitörü

$\left(\mathrm{IC} \gg=27,9^{\wedge} \mathrm{g} / \mathrm{ml}\right)(23)$

HIV-1-integraz inhibitörü

$(\mathrm{IC} \gg=38,5 \mathrm{ng} / \mathrm{ml})(23),(24)$

HIV-1-integraz inhibitörü

$\left(\mathrm{IC}_{50}=28,3^{\wedge} \mathrm{g} / \mathrm{ml}\right)(23),(25)$

HIV-1-integraz inhibitörü

$\left(\mathrm{IC}_{50}=28.0 \mid \mathrm{a}, \mathrm{g} / \mathrm{ml}\right)(23),(26)$

HIV-1-RT inhibitörü

$\left(\mathrm{IC}_{50}=50 \mathrm{nM}\right)(27)$ 
Tüm bitki

Chrysanthemum morifolium

(Compositae)

Çiçekli dal uçları

Erythrina glauca

(Leguminosae) Kök

Erythrina lysistemon

(Leguminosae) Kabuk

Garcinia mangostana

(Guttiferae)

Meyva Kabuğu

Garcinia multiflora

(Guttiferae)

Filizler ve odun

Maclura tinctoria

(Moraceae) Kabuk
Korilagin (38)

1,3,4,6 tetra-O-gallol-P

-D-glukopiranozit (39)

Akasetin-7-0-(3-D-

galaktopiranozit (40)

Krizol (41)

3-0-metilkalopokarpin (42)

Sandviçensin (43)

5-deoksigliyasperin F (44)

2,3 dihidro-2-hidroksi-

neobavaizoflavon (45)

Mangostin (46)

y-mangostin (47)

Robustaflavon (48)

Hinokiflavon (49)

Amentoflavon (50)

Agatisflavon (51)

Makluraksanton B (52)

Makluraksanton C (53)

İzosiklomulberrin (54)
HIV-1-RT inhibitörü

$\left(\mathrm{IC}_{30}=20 \mathrm{plM}\right)$ (27)

HIV-1-RT inhıbitörü

$(\mathrm{IC50}=86 \mid \mathrm{iM})(27)$

HIV replikasyon inhibitörü

$\left(\mathrm{EC}_{50}=8 \mathrm{MM}\right)(28)$

HIV replikasyonu inhibitörü

$\left(\mathrm{EC}_{50}-5^{\wedge} \mathrm{M}\right)$ (28)

HIV'in neden olduğu

sitopatik etkileri inhibe eder

$\left(\mathrm{EC}_{50}=0,2 \mathrm{jig} / \mathrm{ml}\right)(29)$

HIV'in neden olduğu

sitopatik etkileri inhibe eder

$\left(\mathrm{EC}_{50}=7,6 \mathrm{fjM}\right)$

HIV'in neden olduğu

sitopatik etkileri inhibe eder

$($ EC5o=1UMM) (29)

HIV'in neden olduğu

sitopatik etkileri inhibe eder

$\left(\mathrm{EC}_{50}=1,6 \backslash M\right)(29)$

HIV-1-PR inhibitörü

$\left(\mathrm{IC}_{5} \mathrm{O}=5,12^{\wedge} \mathrm{M}\right)(30)$

HIV-1-PR inhibitörü

$(\mathrm{ICJO}=4,81 \mathrm{pM})(30)$

HIV-1-RT inhibitörü

$\left(\mathrm{IC}_{50}=65 \mathrm{MM}\right)(31)$

HIV-1-RT inhibitörü

$\left(\mathrm{IC}_{50}=62 \mathrm{jxM}\right)(31)$

HIV-1-RT inhibitörü

$\left(\mathrm{IC}_{50}=119 \mid \mathrm{iM}\right)(31)$

HIV-1-RT inhibitörü

$\left.\mathrm{aC}_{50}=100 \mathrm{MM}\right)(31)$

HIV replikasyon inhibitörü

$\left(\mathrm{EC}_{50}=1-2 \mathrm{ng} / \mathrm{ml}\right)$ (32)

HIV replikasyon inhibitörü

$\left(\mathrm{EC}_{50}=1,3-2,2 \mathrm{ug} / \mathrm{ml}\right)(32)$

HIV replikasyon inhibitörü

$\left(\mathrm{EC}_{50}=7,5 \mathrm{jig} / \mathrm{ml}\right)(32)$ 
Monotes africanus

(Dipterocarpaceae) Yaprak

Pseudotsuga menziessi

(Pinaceae) Kabuk

Rhus succedanea

(Anacardiaceae) Tohum

Swertia franchetiana

(Gentianaceae) Tüm bitki

Svertipunikozit (64)

$$
\text { GB-la(61) }
$$

GB-2a (62)

Svertifrankezit (63)

Konokurvon (65)

KINONLAR :

Conospermum incurvum

(Proteaceae)

Gövde, filiz ve yaprak

\section{KUMARIINLER:}

Ardisia japonica

(Myrisinaceae)

Toprak üstü

6,8-diprenilkemferol

5'5'-bishidrokersetol

Morelloflavon (60)

60)

6,8-diprenilaromadendrin (55) 
Calophyllum cordata

oblongum (Guttiferae)

Yaprak

Calophyllum inophyllum

(Guttiferae)

\section{Yaprak ve sürgünler}

Calophyllum lanigerum

miq.var. austrocariaceum

(Guttiferae)

Meyva ve sürgünler

Calophyllum teysmanni

(Guttiferae) Lateks

(Convolvulaceae)

\section{Kadsura interior}

(Schizandraceae) Gövde

\section{Litsea verticillata}

(Lauraceae)

Yaprak, filiz,

\section{çiçekli dal uçları}

Schisandra chinensis

(Schisandraceae) Meyva

epiekselsin (80)
Kostatolit (75)

(-)-Artijenin (76)

Kordatolit A (69)

Kordatolit B (70)

İnofillum B (71)

(+)-Kalanolit A (72)

(-)-Kalanolit B (73)

Soulatrolit (74)

(-)-Trakelogenin (77)

Şizanterin D (78)

İnterioterin A (79)

(+)-5'demetoksi-

Gomisin J (81)

$1506(82)$

(Gomisin J'nin Br'lu yarı sentetik türevi)
HIV-1-RTİnhibitörü

$\left(\mathrm{IC}_{50}=12,3 \mathrm{uM}\right)(38)$

HIV-1-RTİnhibitörü

$\left(\mathrm{IC}_{50}=19,0 \mathrm{uM}\right)(38)$

HIV-1-RT inhibitörü

$\left(\mathrm{IC}_{50}=0,038 \mid \mathrm{iM}\right)(4),(12),(39)$

HIV-1-RT inhibitörü

$\left(\mathrm{IC}_{50}=0,32 \mathrm{uM}\right)(4),(12)$

HIV-1-RT inhibitörü

$\left(\mathrm{IC}_{50}=0,2^{\wedge} \mathrm{M}\right)(4),(12)$

HIV-1-RT inhibitörü

$\left(\mathrm{IC}_{50}=0,81 \mathrm{uM}\right)(40),(41)$

HIV-1-RT inhibitörü

$(\mathrm{IC50}=0,2 \mathrm{MM})(4),(12)$

Viral protein üretimini azaltır

HIV-1-RT inhibitörü

HIV-1-integraz inhibitörü (42),(43)

Viral protein üretimini azaltır

HIV-1-RT inhibitörü

HIV-1-integraz inhibitörü (42),(43)

HIV replikasyon inhibitörü

$\left(\mathrm{EC}_{50}=0,5 \mathrm{ng} / \mathrm{ml}\right)(44)$

HIV replikasyon inhibitörü

$\left(\mathrm{EC}_{50}=3, \operatorname{lng} / \mathrm{ml}\right)(44)$

HIV replikasyon inhibitörü

$\left(\mathrm{IC}_{50}=16.4 \mathrm{nM}\right)(45)$

HIV-1-RT inhibitörü

$\left(\mathrm{IC}_{50}=45 \mathrm{plg} / \mathrm{ml}\right)(42),(43)$

HIV-1-RT inhibitörü

$(\mathrm{IC} \gg=\mathrm{jjig} / \mathrm{ml})(21),(43)$ 
Terminalin bellerica

(Combretaceae) Meyva

\section{PEPTITTLER:}

Myrianthus holstü

(Urticaceae) Kök odunu

Policaurea kondensata

(Rubiaceae) Kabuk

Urtica dioica

Rizom

(Urticaceae)

\section{POLISAKKARIITLER:}

Aloe barbadensis

(Liliaceae)

Heparin

Monostroma latissimum

Deniz yosunu (Chlorophyta)

Asparagopsis armata

(Kırmızı alg)

Champio parvula

(Kırmızı alg)

Liagora boergesenii

(Kırmızı alg)
Termilignan (83)

Tannilignan (84)

7-hidroksi-3', 4'-

(metilendioksi)flavan (85)

Anolignan B (86)

M holstü lektin(MHL)

Palikureyin

UDA

Asemannan

Enoksaparin (87)

Ramnan sülfat

Sülfatlanmış galaktanlar

(gametik evrede)

Sülfatlanmış galaktanlar

(tetrasporik evrede)

Sülfatlanmış polisakkaritler

Sülfatlanmış polisakkaritler
HIV antijen üretimini azaltır (46)

HIV antijen üretimini azaltır (46)

HIV antijen üretimini azaltır (46)

HIV antijen üretimini azaltır

HIV-1-RT inhibitörü (46)

HIV'in sitopatik etkilerine karşı koruma $\left(\mathrm{EC}_{50}=150 \mathrm{Nm}\right)$

Sinsitiya formasyon inhibitörü

$\left(\mathrm{EC}_{50}=9,8 \mathrm{ug} / \mathrm{ml}\right)(47)$

HIV'in sitopatik etkilerine karşı korama $(\mathrm{EC} \gg=0.1 \mathrm{OuM})(48)$

HIV'in sitopatik etkilerine karşı koruma $\left(\mathrm{EC}_{50}=105 \mathrm{nM}\right)$

(17), (47), (49)

Sinsitiya formasyonu inhibitörü ve virion üretimini inhibe eder

$\left(\mathrm{IC}_{50}=45 \mathrm{ug} / \mathrm{ml}\right)(4),(50)$

Virüs-hücre, hücre-hücre

birleşmesini inhibe eder (12)

Virüsün konakçı hücrelere

adsorbsiyon inhibitörü (51)

Sinsitiya formasyonu inhibitörü

$\left(\mathrm{IC}_{50}=5,3 \mid \mathrm{ig} / \mathrm{ml}\right)(51)$

HIV replikasyon inhibitörü

Sinsitiya formasyonu inhibitörü (52)

HIV replikasyon inhibitörü

Sinsitiya formasyonu inhibitörü (52)

HIV replikasyon inhibitörü

$\left(\mathrm{EC}_{50}=6,5 \mathrm{ug} / \mathrm{ml}\right)$

Sinsitiya formasyonu inhibitörü (53)

HIV replikasyon inhibitörü

$\left(\mathrm{EC}_{50}=5,2 \mathrm{ug} / \mathrm{ml}\right)$

Sinsitiya formasyonu inhibitörü (53) 
Plocamium leptophyllum

(Kırmızı alg)

Plocamium telfairiae

(Kırmızı alg)

Portieria hornemanni

(Kırmızı alg)

Mavi-yeşil algler

(Cyanophyta)

Fucus vesiculosus

(Kahverengi alg)

(55)

Sargassum ofjîcinale

(Kahverengi alg)

Oscillatoria raoi

(Cyanobacteria)

Oscillatoria trichoide

(Cyanobacteria)

Oscillatoria limnetica

(Cyanobacteria)

Phormidium tenue

(Cyanobacteria)

Scytonema $s p$.

(Cyanobacteria)
Sülfatlanmış polisakkaritler

Sülfatlanmış polisakkaritler

Sülfatlanmış polisakkaritler

Sülfolipitler

Fukoidan

(Sülfatlanmış polisakkarit)

Sülfatlanmış polisakkarit

Sülfokinovozilpiranozil

lipitler

(88), (89), (90), (91)

Sülfokinovozilpiranozil

lipitler

(88), (89), (90), (91)

Sülfokinovozilpiranozil

lipitler

(88), (89), (90), (91)

Sülfokinovozilpiranozil

lipitler

(88), (89), (90), (91)

Sülfokinovozilpiranozil

lipitler

(88), (89), (90), (91)
HIV replikasyon inhibitörü

$\left(\mathrm{EC}_{50}=7,8 \mathrm{ug} / \mathrm{ml}\right)$

Sinsitiya formasyonu inhibitörü (53)

HIV replikasyon inhibitörü

$\left(\mathrm{EC}_{50}=2,6 \mathrm{ug} / \mathrm{ml}\right)$

Sinsitiya formasyonu inhibitörü (53)

HIV replikasyon inhibitörü

$\left(\mathrm{EC}_{5} \mathrm{O}=4,8 \mathrm{ug} / \mathrm{ml}\right)$

Sinsitiya formasyonu inhibitörü (53)

HIV-RT inhibitörleri (54)

HIV-RT inhibitörü

Sinsitiya formasyonu inhibitörü

HIV replikasyon inhibitörü

Sinsitiya formasyonu inhibitörü

$\left(\mathrm{ED}_{50}=4,6 \mathrm{fig} / \mathrm{ml}\right)(53)$

HIV-1-RT inhibitörü (56), (57)

HIV-1-RT inhibitörü (56), (57)

HIV-1-RT inhibitörü (56), (57)

HIV-1-RT inhibitörü (56), (57)

HIV-1-RT inhibitörü (56), (57) 
TANENLER:

Areca catechu

(Palmae) Tohum

Eugenia caryophyllata

(Myrtaceae)

\section{Çiçek tomurcukları}

Maytenus senegalensis

(Celastraceae)

\section{Gövde kabukları}

Phyllantus emblica

(Euphorbiaceae) Meyva

Phyllantus niruri

(Euphorbiaceae) Yaprak

Sepherdia argentea

\section{Yaprak}

(Eleagnaceae)

Swietenia mahagoni

(Meliaceae)

\section{Kabuk}

Tannik asit (Ticari Kaynak)
ProsiyanidinBl (92)

Arekatanin Al (93)

Arekatanin B1 (94)

Ojenin (95)

Kasuyariktin (96)

1,3-di-0-gallol-4,6-(5)-

hekzahidroksidifenol

-(3- D-glukopiranoz (97)

Telimagrandin (98)

(-)-4'-metilepigallokateşin-5

-O-P-D-glukopiranozit (99)

(+)-4'-metilepigallokateşin-3'

-O-P-D-glukopiranozit (100)

Floroglusinol-1-O-3-D-

glukopiranozit (101)

(-)-Epikateşin(4P->8) (-)-

epikateşin (102)

Putranjivayin A (103)

Repandusinik asit A (104)

Sefagenin A (105)

Sefagenin B (106)

Klorojenik asit (107)

Klorojenik asit (108)

metil esteri

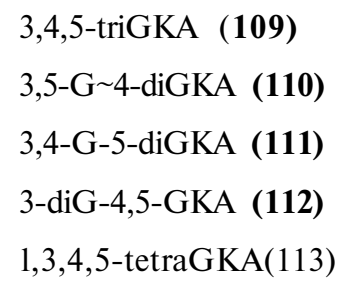

HIV-1-PRinhibitörü(58)

HIV-1-PR inhibitörü (58)

HIV-1-PR inhibitörü (58)

Sinsitiya formasyonu inhibitörü $\left(\mathrm{EC}_{50}=25,71 \mid \mathrm{aM}\right)(59)$

Sinsitiya formasyonu inhibitörü $\left(\mathrm{EC}_{50}=27,60 \mid \mathrm{oM}\right)(59)$

Sinsitiya formasyonu inhibitörü $\left(\mathrm{EC}_{50}=44,38 \mathrm{uM}\right)(59)$

Sinsitiya formasyonu inhibitörü $\left(\mathrm{EC}_{50}=16,2 \mathrm{uM}\right)$ (59)

HIV-1-PR inhibitörü (60)

HIV-1-PR inhibitörü (60)

HIV-1-PR inhibitörü (60)

HIV-1-PR inhibitörü (60)

HIV-1-RT inhibitörü

$\left(\mathrm{IC}_{50}=3,9 \mathrm{uM}\right)(42)$

HIV-1-RT inhibitörü

$\left(\mathrm{IC}_{50}=0,05 \mathrm{uM}\right)(42)$

HIV-1-RT inhibitörü

$($ ICso $=49 n M)(42),(61)$

HIV-1-RT inhibitörü

$(\mathrm{IC50}=7 \mathrm{nM})(42),(61)$

HIV-I-PR inhibitörü (62)

HIV-l-PR inhibitörü (62)

HIV-1-RT inhibitörü (63)

HIV-1-RT inhibitörü (63)

HIV-1-RT inhibitörü (63)

HIV-1-RT inhibitörü (63)

HIV-1-RT inhibitörü (63) 


\section{TRITTERPENLER :}

Aesculus chinensis

(Hippocastanaceae)Tohum

Geum japonicum

(Rosaceae) Tüm bitki

\section{Gleditsia japonica}

(Leguminosae)Meyva

Glycyrrhiza glabra

(Leguminosae) Kök

Glycine mex-Merrill

(Fabaceae) Tohum

Gymnocladus chinensis

(Leguminosae) Meyva

Hyptis capitata

(Labiatae) Tüm bitki

Kadsura lancilimba

(Schizandraceae)

Kök ve gövde

Maprounea africana

(Euphorbiaceae) Kök
Essin la (114)

HIV-1-PR inhibitörü (64)

Essin $\mathrm{Ib}$ (115)

HIV-1-PRİnhibitörü(64)

2-oc,19-a-dihidroksi-3-

okso-12-ursen-28-oik asit

(116)

Ursolik asit (117)

Maslinik asit (118)

Gleditsiya saponin C (119)

Glisirizin (120)

Glikokumarin (121)

Likopiranokumarin (122)

Likokalkon A (123)

İzolikoflavonol (124)

Glisirizoflavon (125)

Soyasaponin II (126)

Gimnokladus G (127)

Pomolik asit (128)

Oleanolik asit (129)

Ursolik asit (117)

Lansilakton C (130)

1 -P-hidroksialöritolik

asit (131)
HIV-1-PR inhibitörü (64)

HIV-1-PR inhibitörü (65)

HIV-1-PR inhibitörü (65)

HIV replikasyon inhibitörü

$\left(\mathrm{EC}_{50}=\mathrm{UjiM}\right)(66)$

HIV replikasyon inhibitörü (67), (68)

Sinsitiya formasyonu inhibitörü

(67), (68)

Sinsitiya formasyonu inhibitörü

(67), (68)

Sinsitiya formasyonu inhibitörü

(67), (68)

Sinsitiya formasyonu inhibitörü

(67), (68)

Sinsitiya formasyonu inhibitörü (67), (68)

HIV replikasyon inhibitörü

$\left(\mathrm{IC}_{50}=\mathrm{H} 2 \mid \mathrm{iM}\right)(69)$

HIV replikasyon inhibitörü

$\left(\mathrm{EC}_{50}=2,7 \mathrm{jxM}\right)(66)$

HIV replikasyon inhibitörü

$\left(\mathrm{EC}_{50}=1,4^{\wedge} \mathrm{g} / \mathrm{ml}\right)(70),(71)$

HIV replikasyon inhibitörü

$\left(\mathrm{IC}_{50}=1,7 \mid \mathrm{ig} / \mathrm{ml}\right)(70),(71)$

HIV replikasyon inhibitörü

$\left(\mathrm{EC}_{50}=2,0 \mathrm{ng} / \mathrm{ml}\right)(70),(71)$

HIV replikasyon inhibitörü

$\left(\mathrm{EC}_{50}=1,4 \mid \mathrm{ag} / \mathrm{ml}\right)(72)$

HIV-1-RT inhibitörü

(İÇ» $=3,7 \mathrm{MM})$

HIV-2-RT inhibitörü

$\left(\mathrm{IC}_{50}=S 9 \mid x M\right)(42)$ 
Panax zingiberensis

(Araliaceae) Kök

Phoradendron juniperinum

(Loranthaceae) Tüm bitki

Polyalthia suberosa

(Annonaceae)

\section{Yaprak ve gövde}

Prosopis glandulosa

(Leguminosae)

\section{Yaprak ve filizler}

Propolis

Rosa woodsü

(Rosaceae) Yaprak

Schisandra sphaerandra

(Schisandraceae) Gövde

Syzygium claviflorum

(Myrataceae) Yaprak

Ternstromia gymnanthera

(Theaceae) Toprak üstü

Tripterygium wilfordü

(Celastraceae) Kök

Xanthoceras sorbifolia

(Sapindaceae) Odun
Zingibrozit (132)

Oleanolik asit (129)

Ursolik asit (117)

Suberosol (133)

Ursolik asit (117)

Moronik asit (134)

3-(3,4-dimetoksifenil)-

2-propenal (135)

Pomolik asit (128)

Oleanolik asit (129)

Nigranoik asit (136)

Betulinik asit (137)

Platanik asit (138)

Dihidrobetulinik asit (139)

Oleanolik asit (129)

Betulinik asit (137)

Salaspermik asit (140)

3 -oksotirukalla-7,24-dien-

21-oik asit (141)

Oleanolik asit (129)

Epigallokateşin-(4(3->8,

2(3->0-7)-epikateşin
HIV'in neden olduğu sitopatik etkileri inhibe eder (73)

(70), (71)

(70), (71)

HIV replikasyon inhibitörü

$\left(\mathrm{EC}_{50}=3^{\wedge} \mathrm{g} / \mathrm{ml}\right)(74)$

(70), (71)

HIV replikasyon inhibitörü

$\left(\mathrm{EC}_{50}=<0,1 \mid \mathrm{ag} / \mathrm{ml}\right)(75)$

HIV replikasyon inhibitörü

$\left(\mathrm{EC}_{50}=2,19 \mathrm{ng} / \mathrm{ml}\right)(75)$

(70), (71)

(70), (71)

HIV-lve HIV-2-RT inhibitörü

$\left(\mathrm{IC}_{50}=74 \mathrm{ng} / \mathrm{ml} ; 167 \mathrm{fxg} / \mathrm{ml}\right.$ (76)

HIV replikasyon inhibitörü

$\left(\mathrm{EC}_{50}=1,4 \mathrm{MM}\right)(77)$

HIV replikasyon inhibitörü

$\left(\mathrm{EC}_{50}=6,5 \mathrm{jiM}\right)$ (77)

HIV replikasyon inhibitörü

$\left(\mathrm{EC}_{50}=0,9 \mathrm{MM}\right)(77)$

(70), (71)

(70), (71)

HIV replikasyon inhibitörü

$\left(\mathrm{EC}_{50}=5 \mid \mathrm{ag} / \mathrm{ml}\right)$

HIV-1-RT inhibitörü

$\left(\mathrm{IC}_{50}=25 \mid \mathrm{ig} / \mathrm{ml}\right)(78)$

HIV-l-PR inhibitörü

$(\mathrm{IC})=20 \mathrm{ng} / \mathrm{ml})(79)$

HIV-1-PR inhibitörü

$\left(\mathrm{IC}_{50}=10 \mathrm{ug} / \mathrm{ml}\right)(79)$

HIV-1-PR inhibitörü

ÖÇ» $=70[\mathrm{ig} / \mathrm{ml})(79)$

(142)

* literatürlerde bitkinin kullanılan kısımları verilmediği için tabloya yazılamamıştır. 
<smiles>OC1CCN2C[C@H](O)C(O)[C@H](O)C12</smiles>

(1)<smiles>CN1CCCCC1c1c(O)cc(O)c2c(=O)cc(-c3ccccc3)oc12</smiles>

(2)<smiles>[2H][C@@]1(CC)CN2CCc3cc(OC)c(OC)cc3[C@H]2C[C@H]1CC1=NCCc2cc(OC)c(OC)cc21</smiles>

(3)<smiles>CC[C@H]1CN2CCc3cc(OC)c(OC)cc3[C@H]2C[C@H]1CC1=NCCc2cc(O)c(OC)cc21</smiles><smiles>C=CC(C)(C)C1(CC=C(C)C)C(=O)Nc2ccccc2C1=O</smiles>

(5)<smiles>CC(C)=CCOC1c2ccccc2NC(=O)C1CC=C(C)C</smiles>

(6)

(4)<smiles>COc1cnc2ccc(=O)n3c4ccccc4c1c23</smiles>

(7)<smiles>CCC(C)=C(C)Oc1cc(CC2c3cc(OC)c(OC)cc3-c3cc(OC)c(OC)cc3CCN2C)ccc1O</smiles>

(12)<smiles>[R]C1[C@@H](O)[C@@H](O)[C@H](O)C(CO)N1CCO</smiles>

$\mathrm{R}=\mathrm{H} ; 2 \alpha-\mathrm{OH}(\mathbf{8})$<smiles>Cc1cc(=O)c2c(O)cc3c(c2o1)C1CCNC(=O)C1[C@H](O)C3</smiles>

(9)<smiles>CCN(C)C(C)(C)C</smiles>

(13)<smiles>COC1=C2C3Cc4ccc(OC)c(O)c4C4(CC3CC24)CC(OC)C1OC(C)=O</smiles>

(11) 


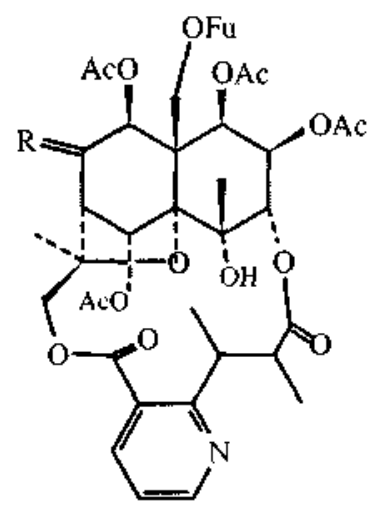

$\mathrm{R}=\beta$-OAc. $\alpha-\mathrm{H} \quad$ (14)<smiles>[R20]C1CC[C@@]2(C)C(CC=C3C=COC3=O)C(=C)CCC2C1(C)C=O</smiles>

$\mathrm{R}_{1}=\mathrm{COCH} 2 \mathrm{CH}_{2} \mathrm{COOH} \quad \mathrm{R}_{2}=\mathrm{H}$ $\mathrm{R}_{\mathrm{l}=\mathrm{H}} \quad \mathrm{R}_{2}=\mathrm{COCH} 2 \mathrm{CH} 2 \mathrm{COOH}$

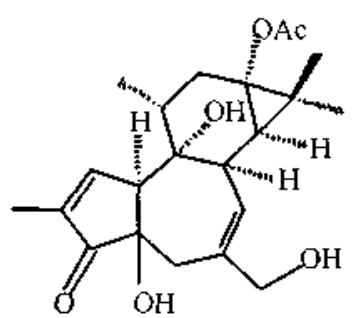

(21)

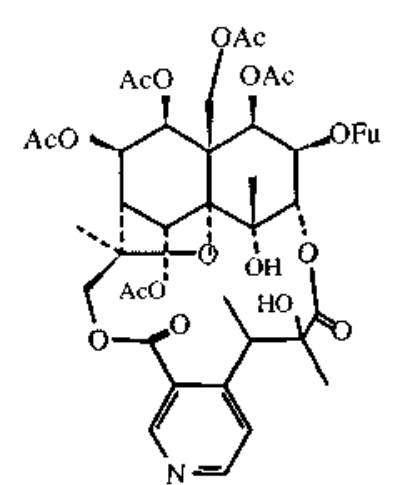

(15)

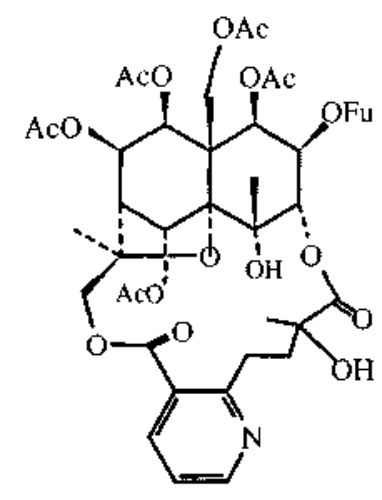

(16)

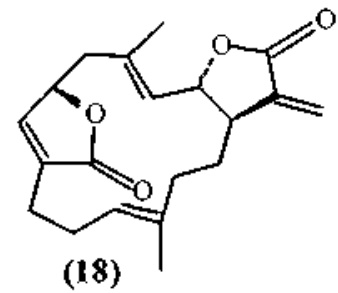

(18)
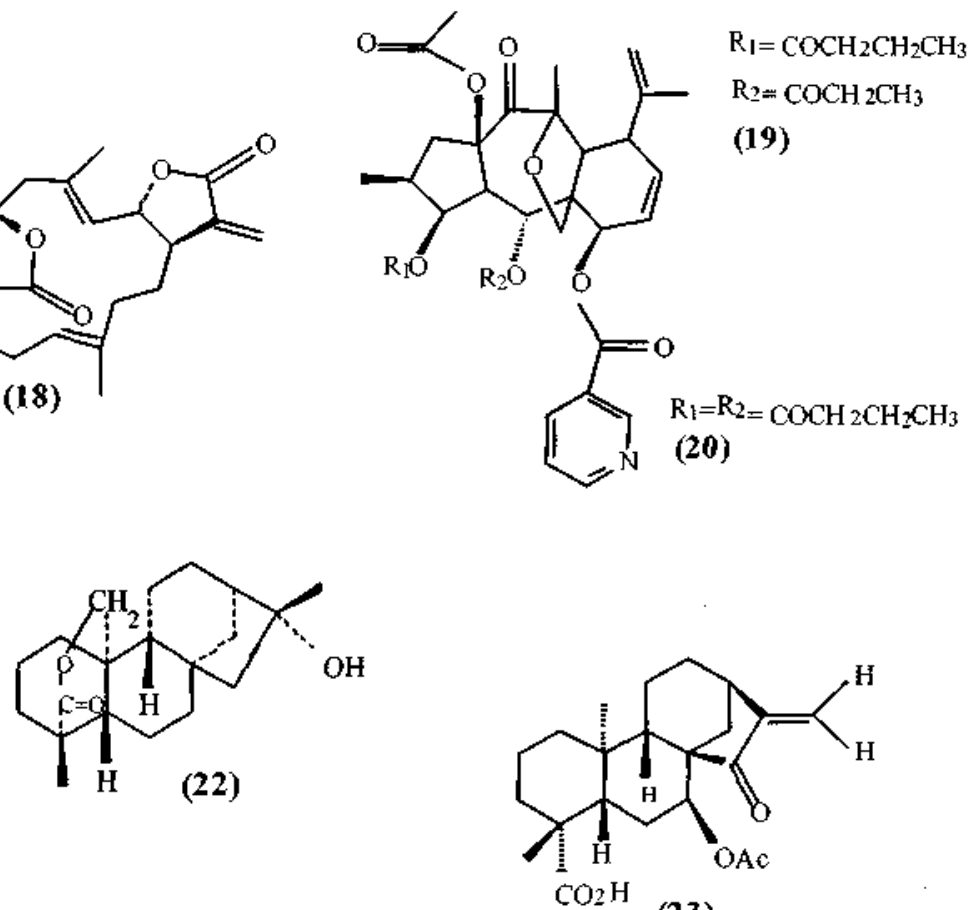

(23)<smiles>CC(=O)OC(Cc1ccc(O)c(O)c1)CC(O)(OC(=O)C1=Cc2cc(O)c(O)cc2[C@H](c2ccc(O)c(O)c2)C1C(=O)O)C(=O)O</smiles>

$\mathrm{R}$ $\mathrm{Na} ; \mathrm{H} \quad(\mathbf{2 4})$

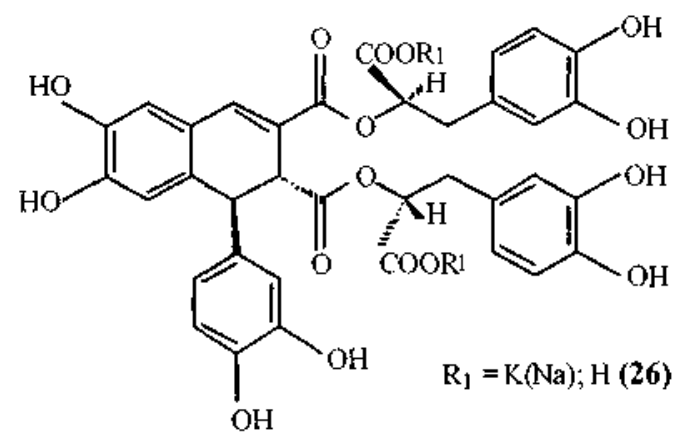


<smiles>[Y6]C(C(=O)[O-])C(Cc1ccc(O)c(O)c1)OC(=O)/C=C/c1ccc(O)c2c1OC(c1ccc(O)c(O)c1)C2C(=O)[O-]</smiles>

(27)

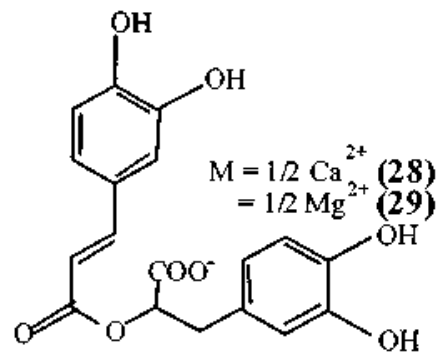<smiles>COc1cc(/C=C/C(O)=C/[C@H](O)/C=C/c2ccc(O)c(OC)c2)ccc1O</smiles>

(30)<smiles></smiles>

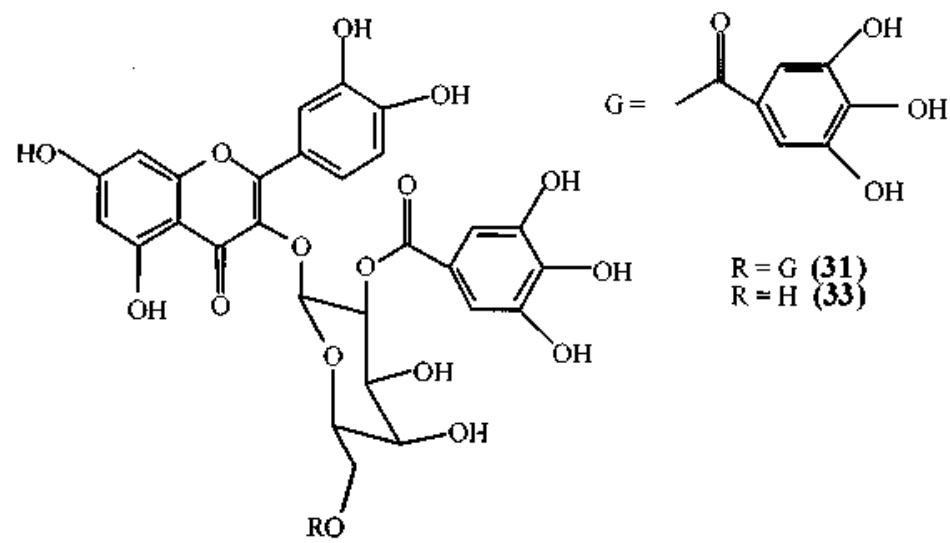<smiles>COC(=O)c1cc(O)c(O)c(O)c1</smiles>

(34)

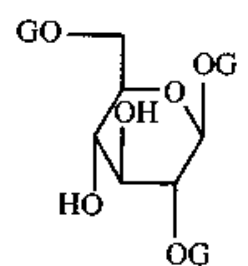

(35)<smiles>Oc1cc(O)c(O)c(O)c1</smiles>

(36)

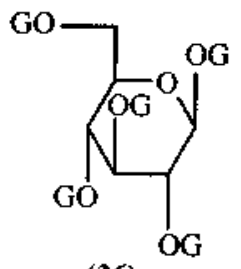




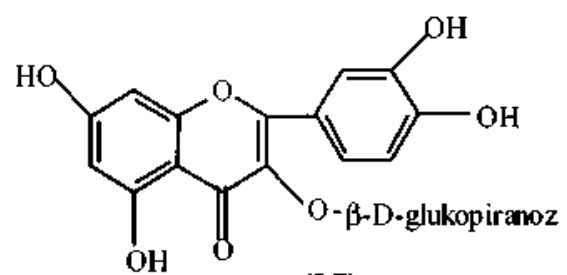

(37)<smiles>O=C(OCC1C(C(=O)Oc2cc(O)c(O)c(O)c2)OC(OC(=O)c2cc(O)c(O)c(O)c2)C(O)C1OC(=O)c1cc(O)c(O)c(O)c1)c1cc(O)c(O)c(O)c1</smiles>

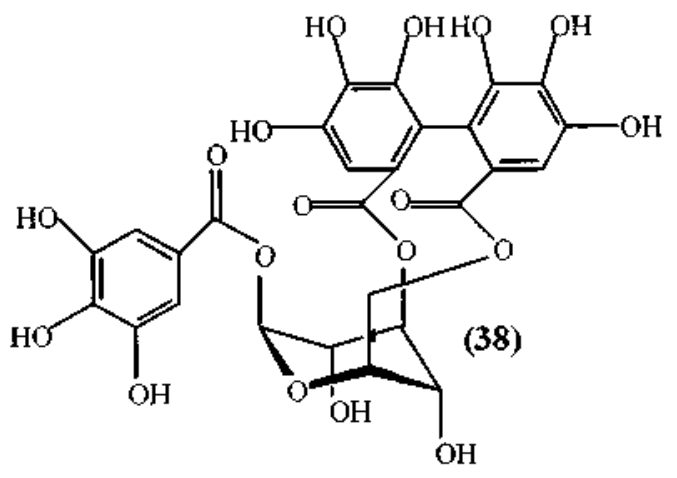

$\beta$-D-galaktopiranoz-Q<smiles>COc1ccc(-c2cc(=O)c3c(O)cc(C)cc3o2)cc1</smiles>

(40)<smiles>O=c1cc(-c2ccccc2)oc2cc(O)cc(O)c12</smiles>

(41)<smiles>COc1cc2c(cc1CC=C(C)C)[C@H]1Oc3cc(O)ccc3[C@@H]1CO2</smiles><smiles>COc1ccc2c(c1CC=C(C)C)O[C@H]1COc3cc(O)ccc3[C@H]21</smiles> 
<smiles>CC1(C)C=Cc2c(O)ccc(C3COc4cc(O)ccc4C3=O)c2O1</smiles>

(44)

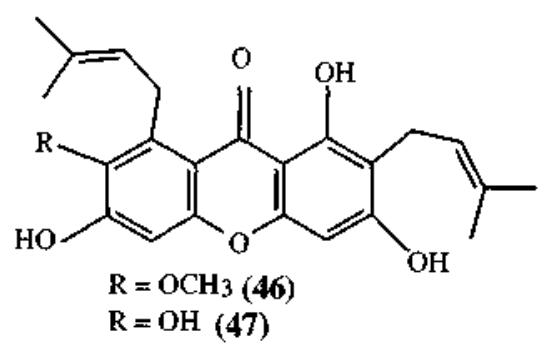<smiles>CC(C)=CCc1c(O)ccc(C2COc3cc(O)ccc3C2=O)c1O</smiles>

(45)<smiles>O=c1cc(-c2ccc(O)c(-c3c(O)cc4oc(-c5ccc(O)cc5)cc(=O)c4c3O)c2)oc2cc(O)cc(O)c12</smiles><smiles>O=c1cc(-c2ccc(Oc3c(O)cc4oc(-c5ccc(O)cc5)cc(=O)c4c3O)cc2)oc2cc(O)cc(O)c12</smiles><smiles>O=c1cc(-c2ccc(O)c(-c3c(O)cc(O)c4c(=O)cc(-c5ccc(O)cc5)oc34)c2)oc2cc(O)cc(O)c12</smiles><smiles>O=c1cc(-c2ccc(O)cc2)oc2cc(O)c(-c3c(O)cc(O)c4c(=O)cc(-c5ccc(O)cc5)oc34)c(O)c12</smiles> 
<smiles>C=CC(C)(C)c1c(O)c(CC=C(C)C)c2oc3cc(O)c(O)cc3c(=O)c2c1O</smiles>

(52)<smiles>C=CC(C)(C)c1c(O)c(CC=C(C)C)c2oc3c(O)c(O)ccc3c(=O)c2c1O</smiles>

(53)<smiles>CC(C)=CCc1c(O)cc2oc3c(c(=O)c2c1O)C(C=C(C)C)Oc1cc(O)ccc1-3</smiles><smiles>CC(C)=CCc1c(O)c(CC=C(C)C)c2c(c1O)C(=O)[C@H](O)[C@@H](c1ccc(O)cc1)O2</smiles><smiles>O=C1c2c(O)cc(O)cc2O[C@H](c2ccc(O)c(O)c2)C1O</smiles>

(58)<smiles>O=C1c2c(O)cc(O)cc2O[C@H](c2cc(O)c(O)c(-c3cc([C@H]4Oc5cc(O)cc(O)c5C(=O)[C@H]4O)cc(O)c3O)c2)C1O</smiles> 

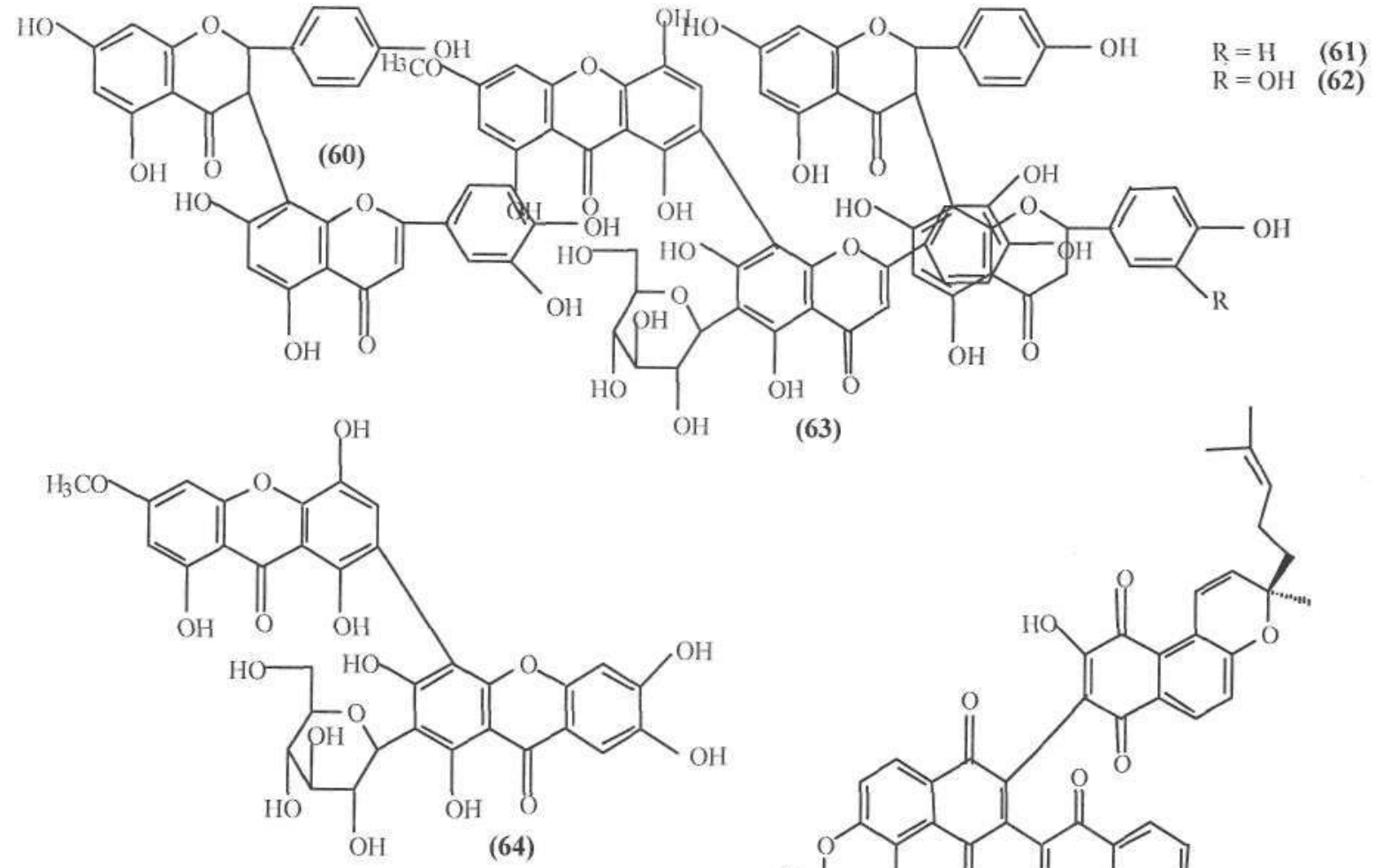

(63)
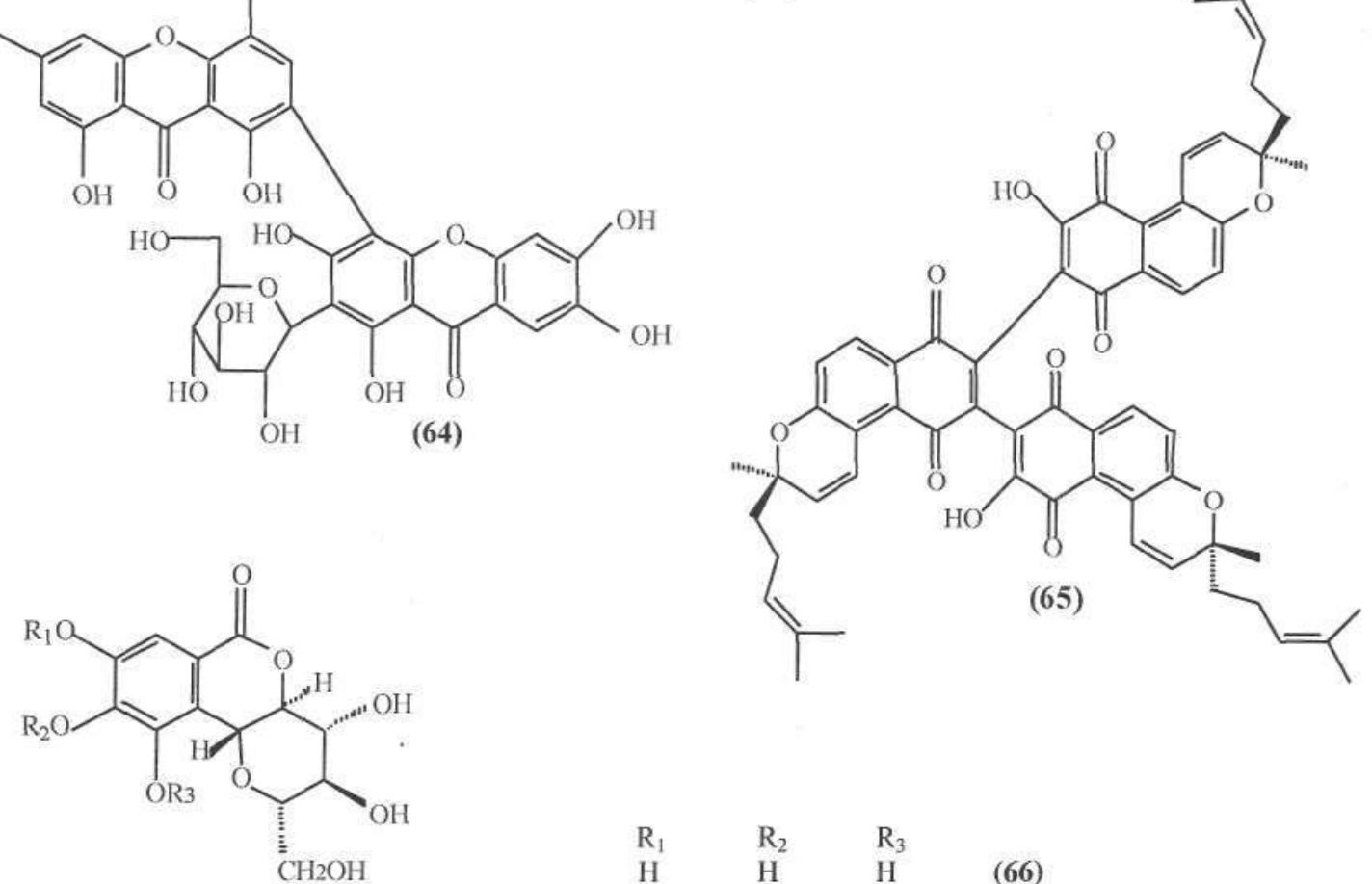

$\begin{array}{llll}\mathrm{R}_{1} & \mathrm{R}_{2} & \mathrm{R}_{3} & \\ \mathrm{H} & \mathrm{H} & \mathrm{H} & \mathbf{( 6 6 )} \\ \mathrm{H} & \mathrm{CH}_{3} & \mathrm{H} & \mathbf{( 6 7 )} \\ \mathrm{CH}_{3} & \mathrm{CH}_{3} & \mathrm{CH}_{3} & \mathbf{( 6 8 )}\end{array}$

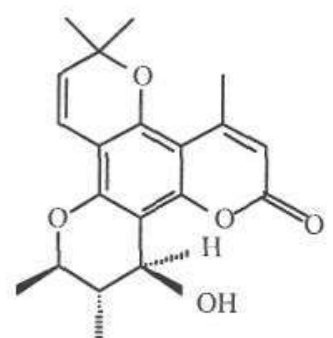

(69)

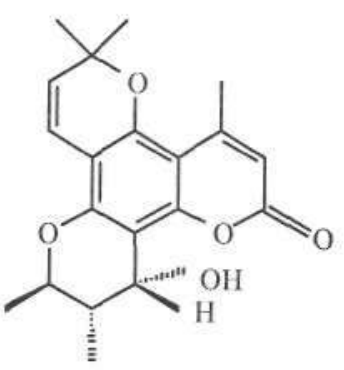

(70)<smiles>CC1Oc2c3c(c4oc(=O)cc(-c5ccccc5)c4c2OC(C)(C)C=C3)[C@H](O)[C@@H](C)[C@@H]1C</smiles>

(71) 
<smiles>CCCc1cc(=O)oc2c3c(c4c(c12)OC(C)(C)C=C4)O[C@H](C)[C@H](C)[C@H]3O</smiles>

(72)<smiles>CCCc1cc(=O)oc2c3c(c4c(c12)OC(C)(C)C=C4)O[C@H](C)[C@H](C)[C@H]3O</smiles>

(73)<smiles>C[C@H]1[C@H](O)c2c(c3c(c4c(-c5ccccc5)cc(=O)oc24)OC(C)(C)C=C3)O[C@@H]1C</smiles>

(74)<smiles>CCCc1cc(=O)oc2c3c(c4c(c12)OC(C)(C)C=C4)O[C@H](C)[C@H](C)[C@H]3O</smiles>

(75)<smiles>COc1cc(C[C@H]2C(=O)OC[C@H]2Cc2ccc(OC)c(OC)c2)ccc1O</smiles>

(76)

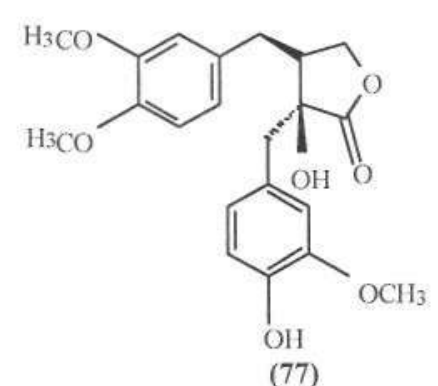

(77)
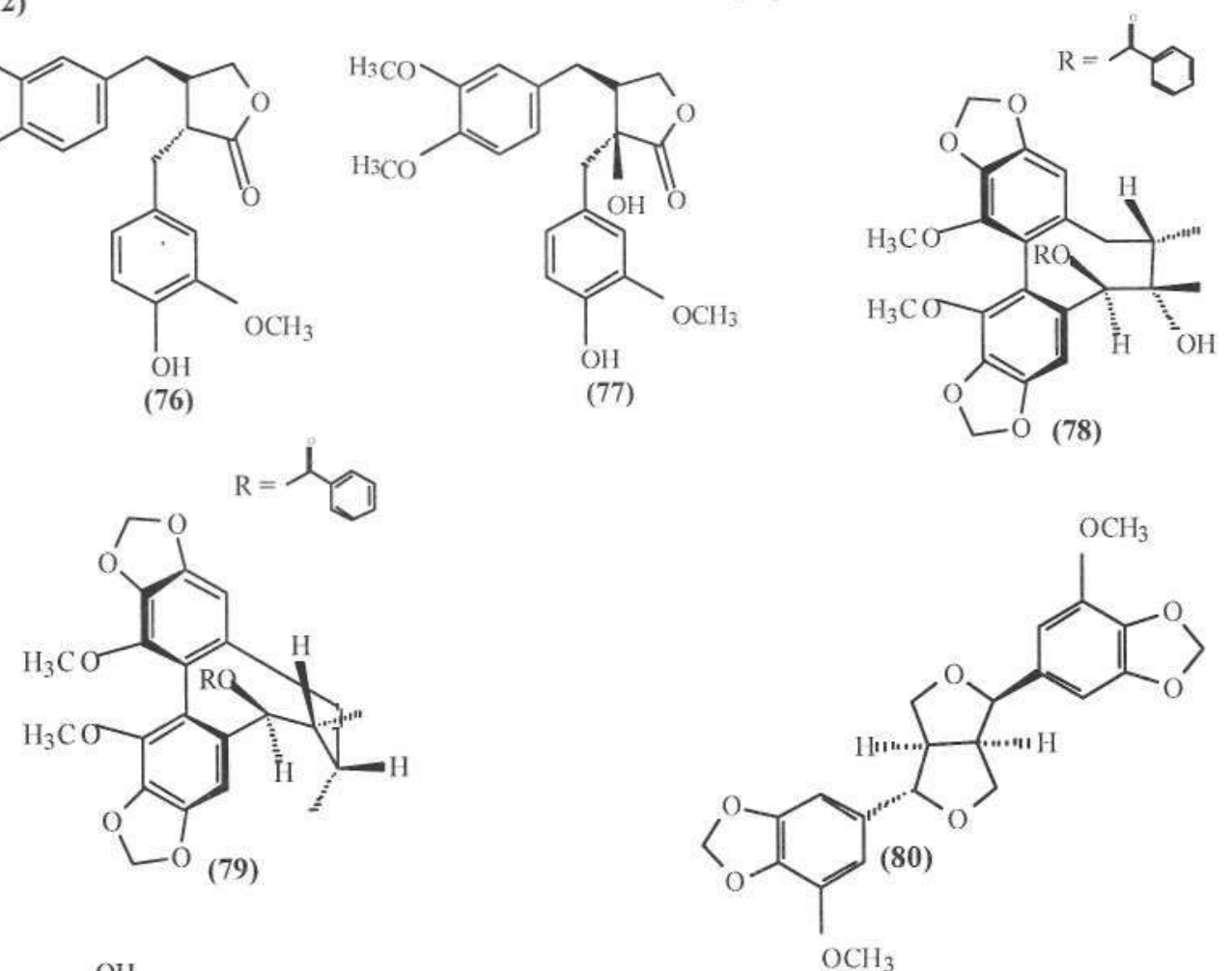<smiles></smiles><smiles>[R]O[R3]([H])([H])Cc1ccc(O)cc1CC(=C)C(O)(CO)Cc1ccc(OC)cc1O</smiles><smiles>Oc1ccc2c(c1)OC(c1ccc3c(c1)OCO3)CC2</smiles>

(84) 


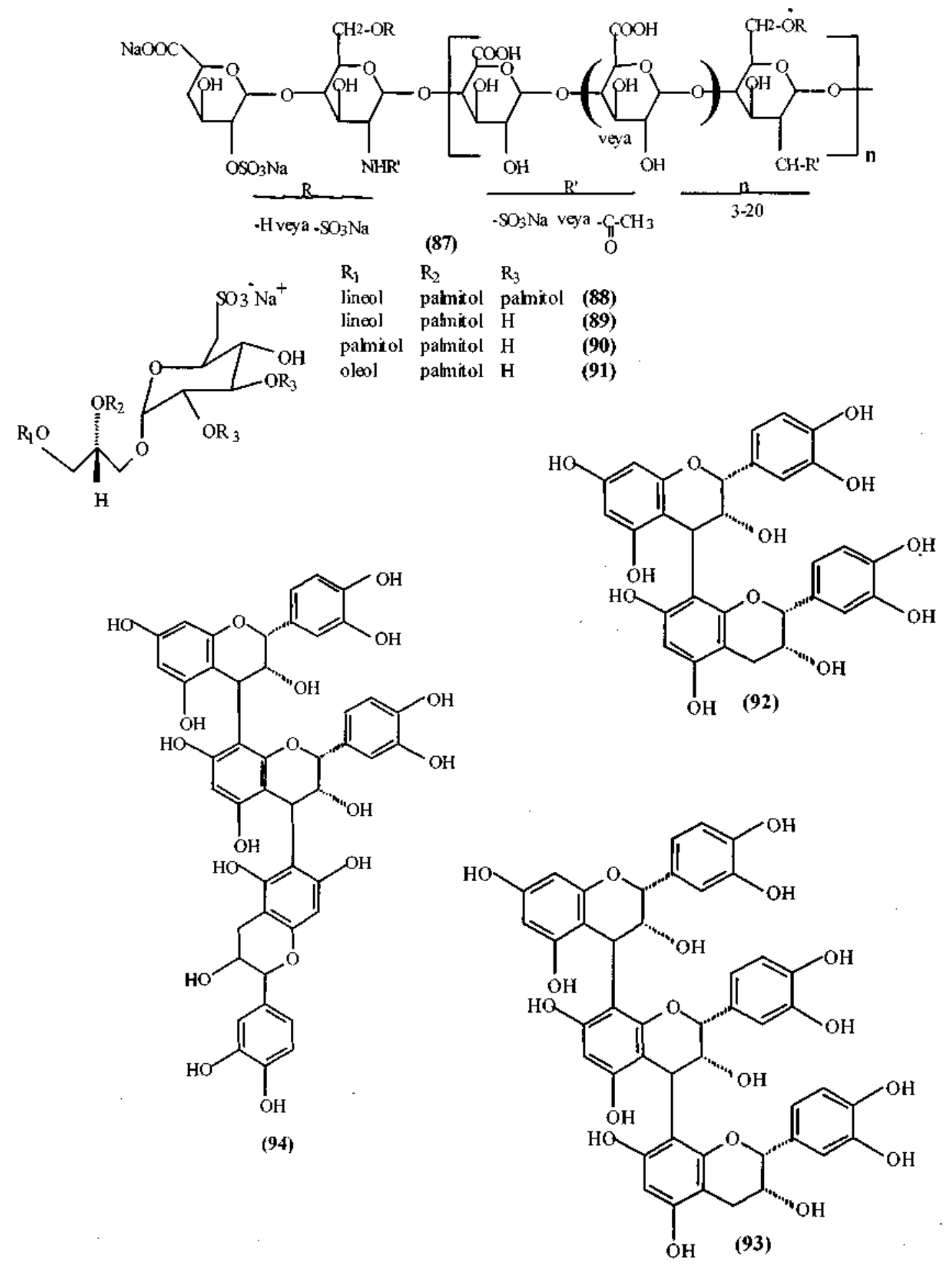




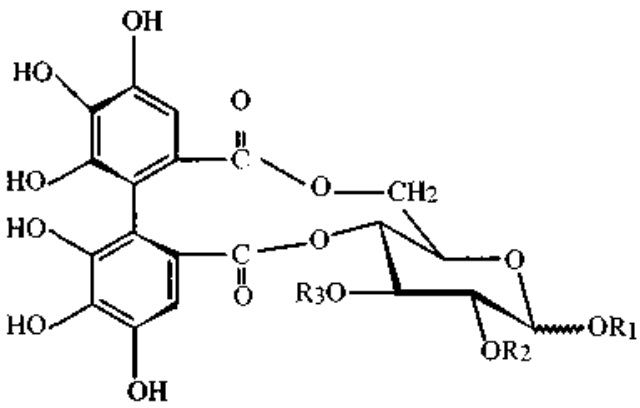<smiles>CC(=O)c1cc(O)c(O)c(O)c1</smiles>

$\begin{array}{llll}\mathrm{R}_{1} & \mathrm{R}_{2} & \mathrm{R}_{3} & \\ \text { B-G } & \mathrm{G} & \mathrm{G} & \mathbf{( 9 5 )} \\ \text { B-G } & (\mathrm{S}) \mathrm{HHDP} & & \mathbf{( 9 6 )} \\ \text { B-G } & \mathrm{H} & \mathrm{G} & \mathbf{( 9 7 )} \\ \text { H } & \mathrm{G} & \mathrm{G} & \mathbf{( 9 8 )}\end{array}$<smiles>COc1c(O)cc([C@@H]2Oc3cc(O)cc(OCl)c3C[C@H]2O)cc1O</smiles>

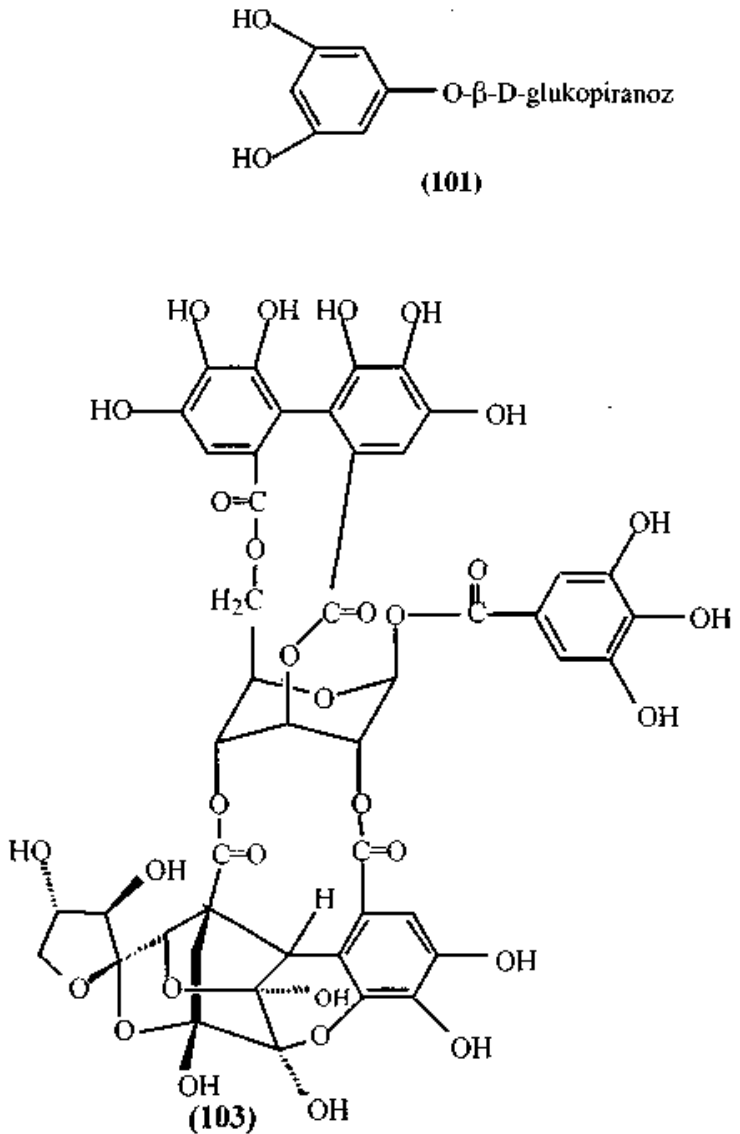

(101)

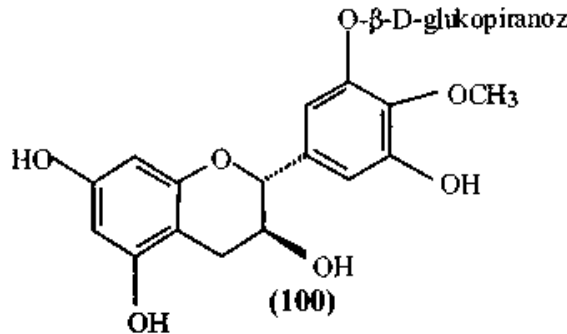

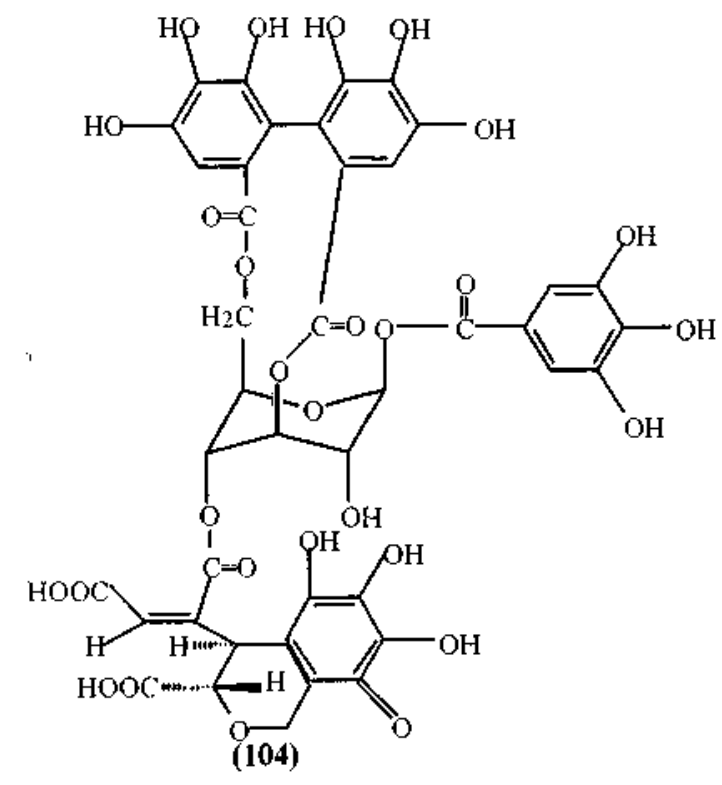



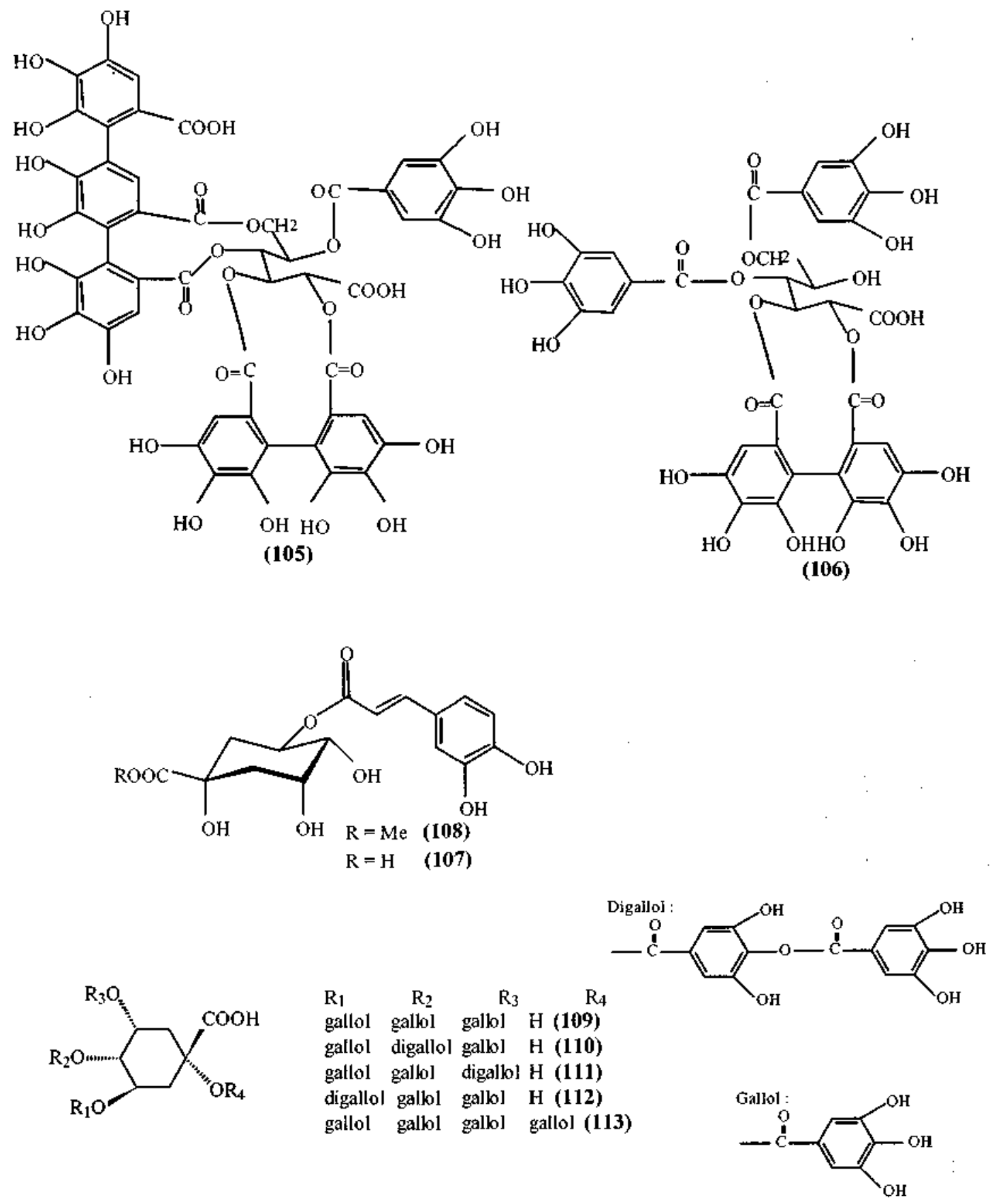


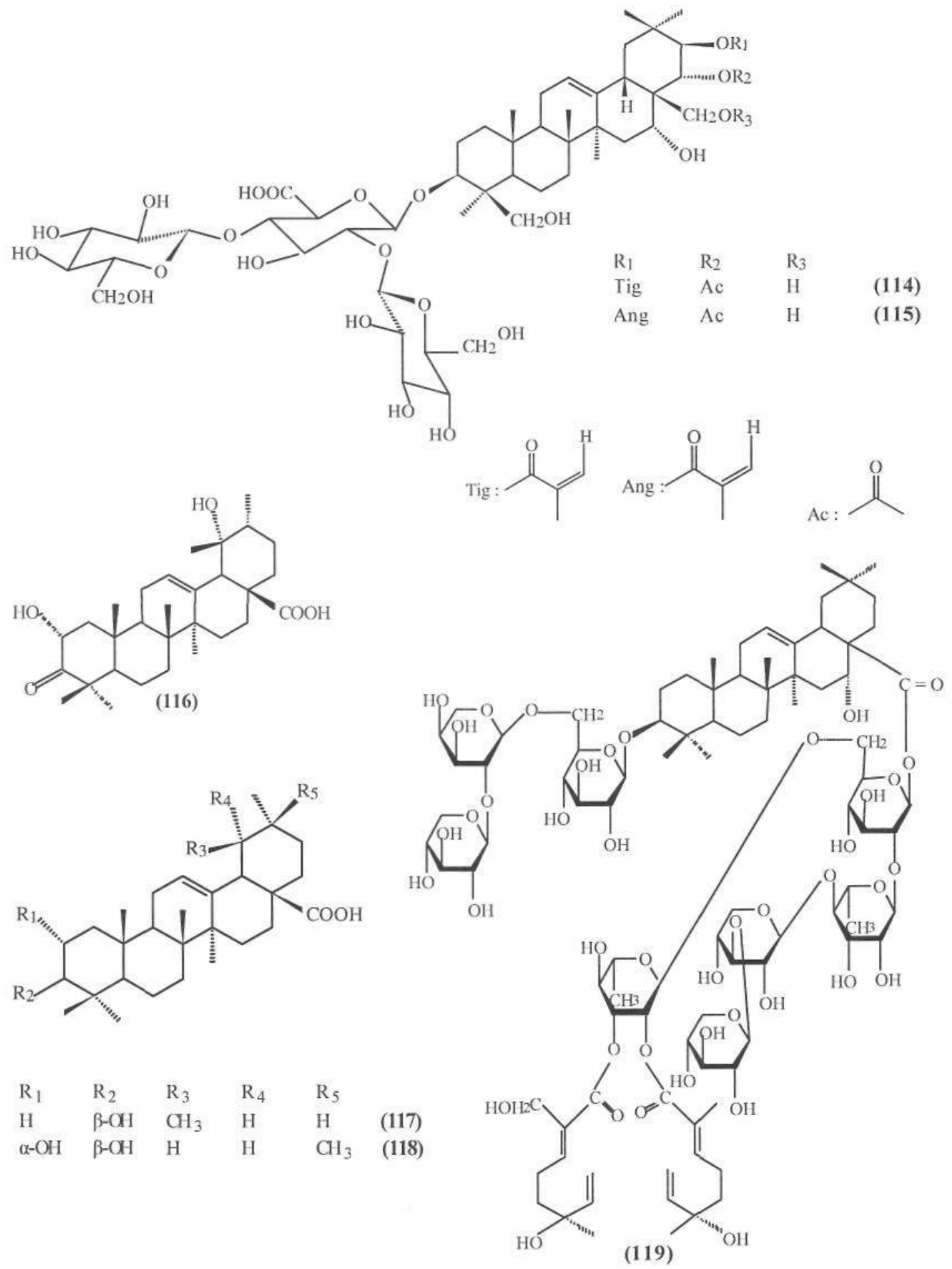



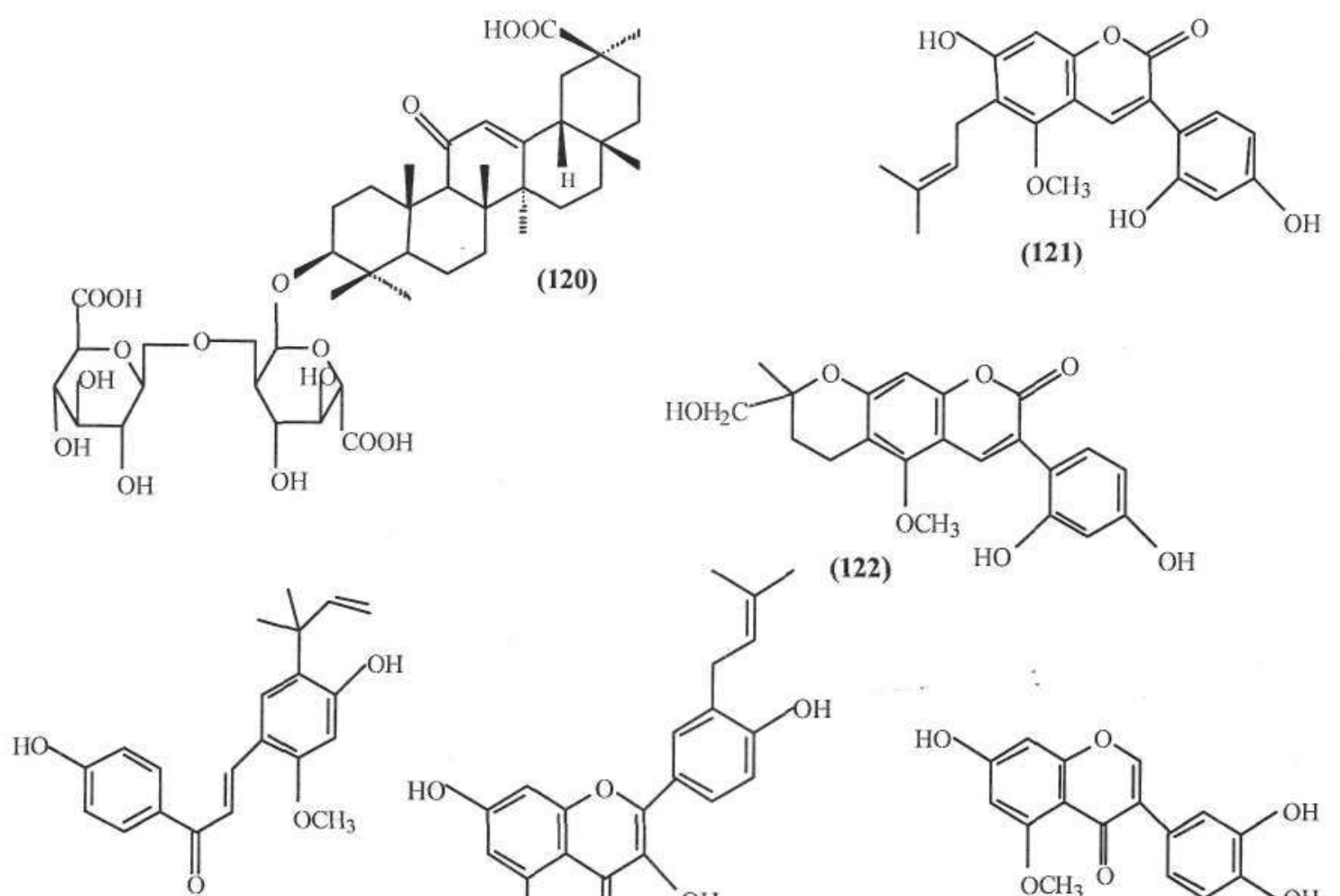<smiles>CC(C)=CCc1cc(-c2oc3cc(O)cc(O)c3c(=O)c2O)ccc1O</smiles>

(122)<smiles>CCCCOc1c2c(cc3oc(=O)c(-c4ccc(O)cc4O)cc13)OC(C)(CO)CC2</smiles>

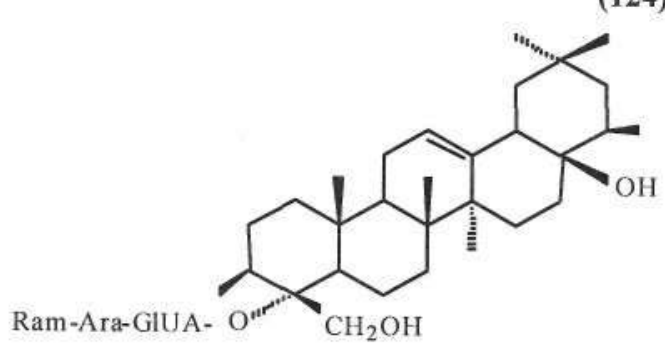

(126)

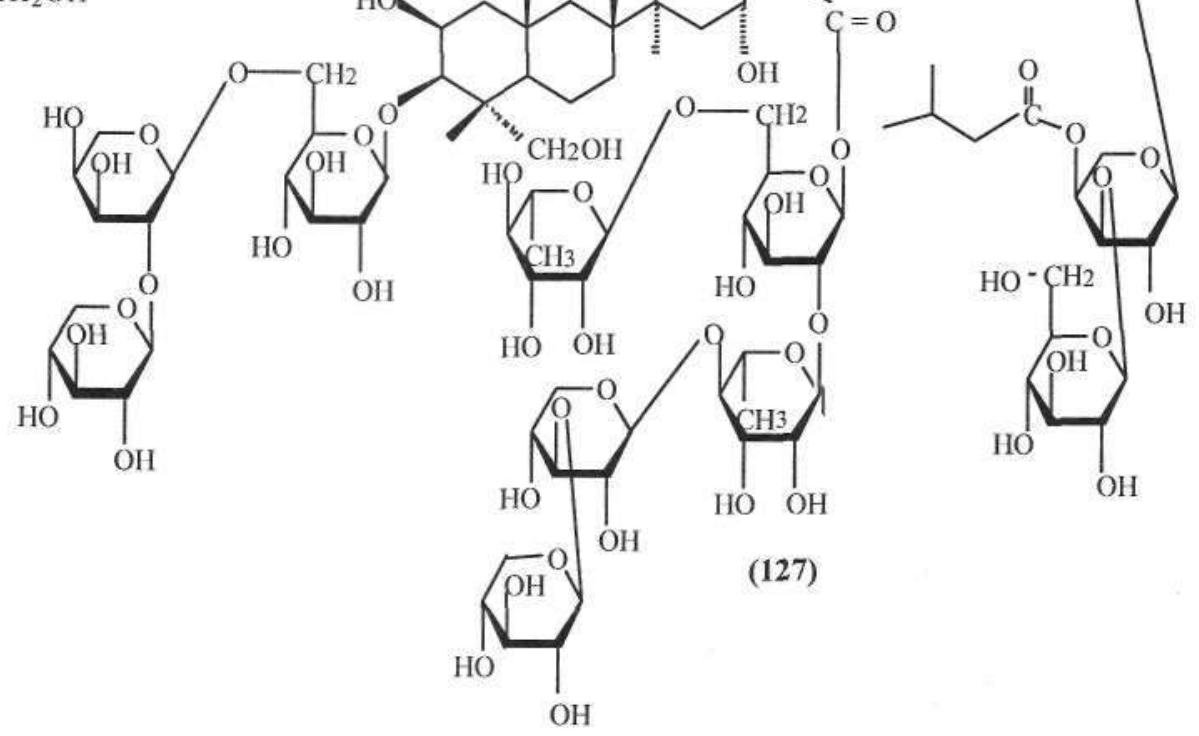



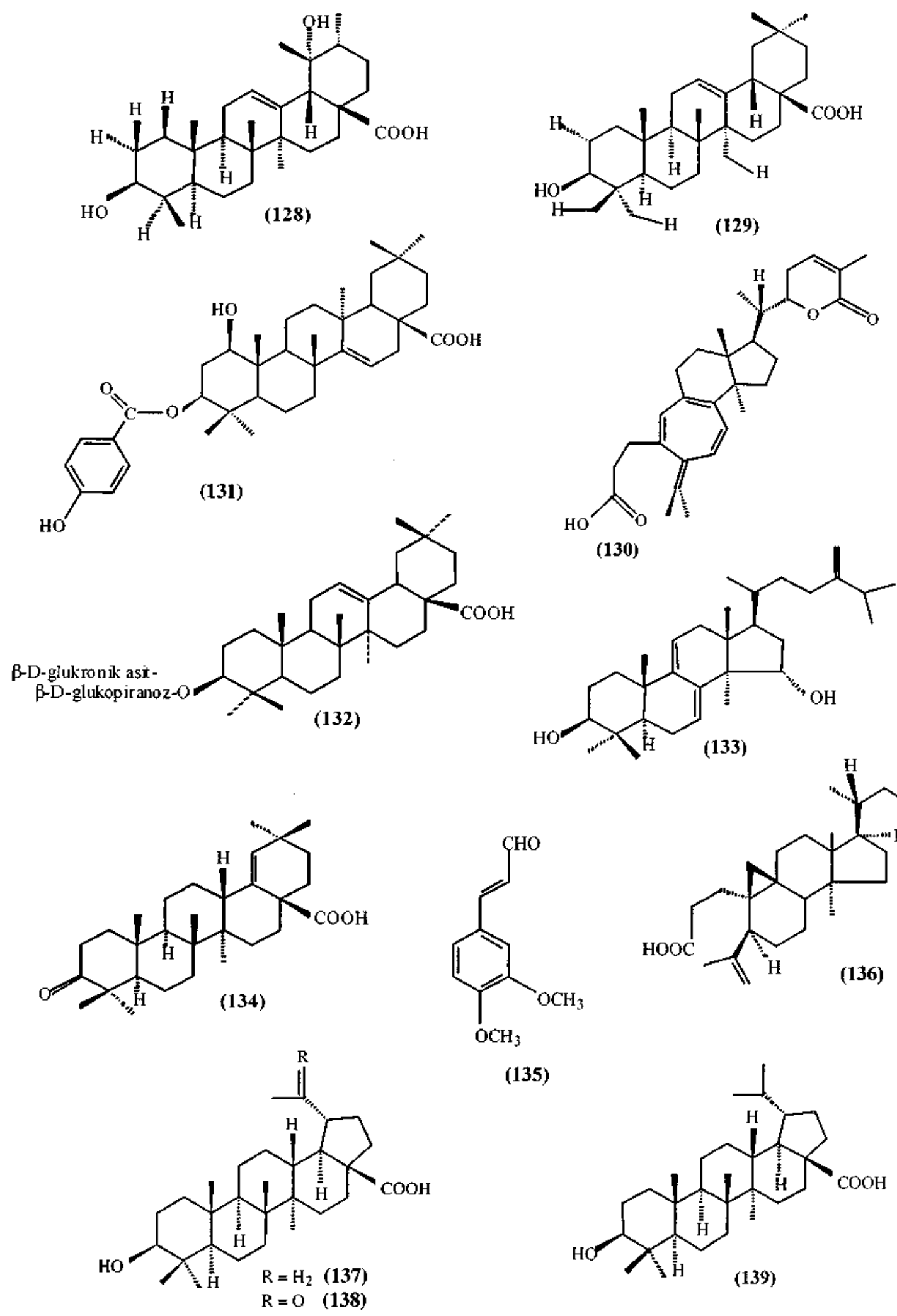

(135)

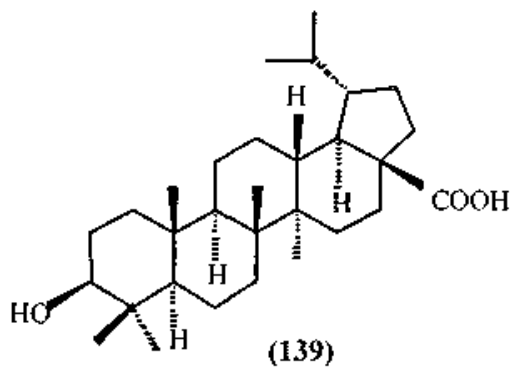




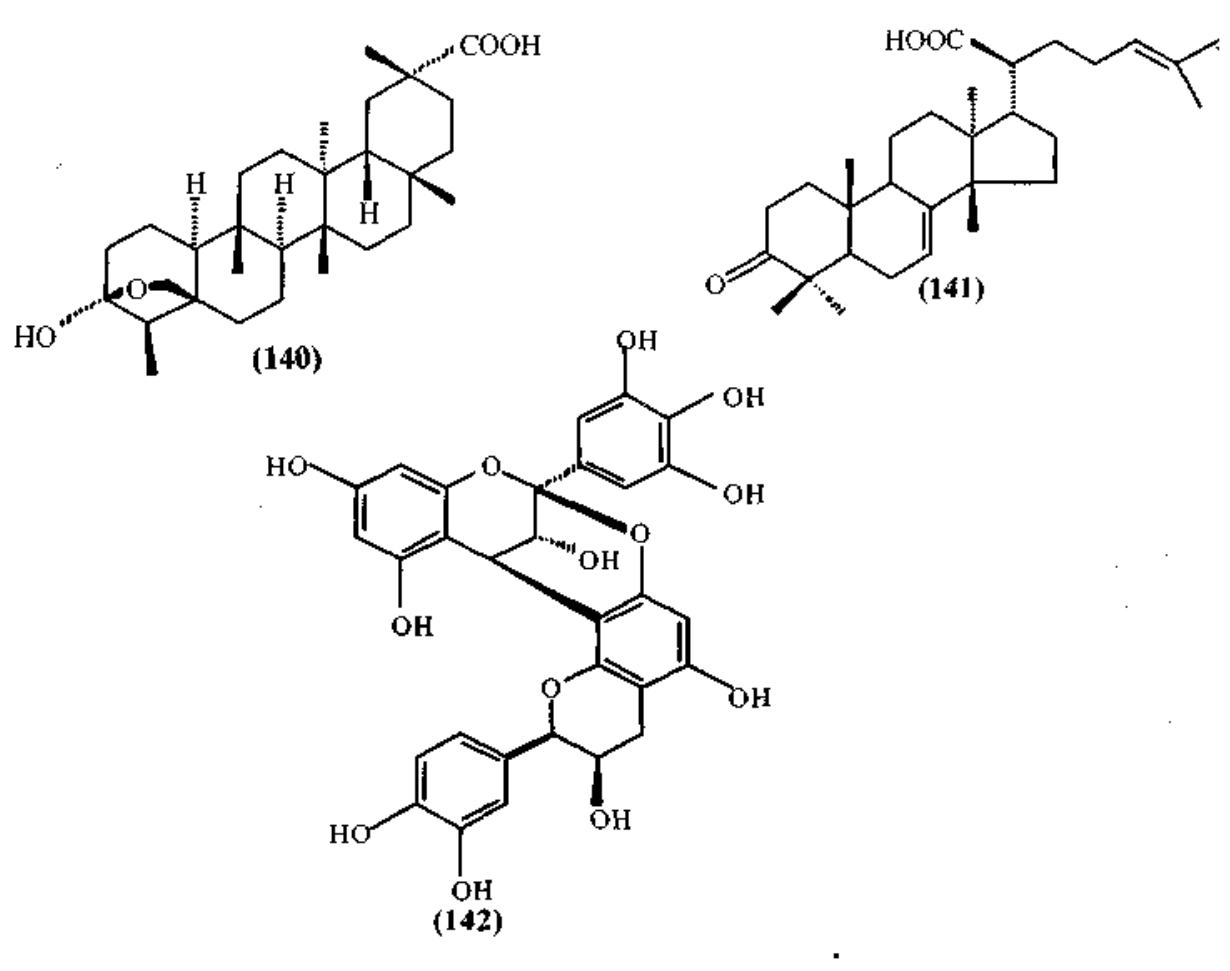

\section{SONUÇ:}

Bitkiler üzerinde yapılan araştırmalarda, 150'yi aşkın bitkiden hazırlanan ekstrelerin veya izole edilen birçok bileşiğin anti-HIV aktivite gösterdiği tespit edilmiştir.

Aktivite gösteren tüm bileşiklerin klinik çalışmaları henüz tam olarak yapılmadı̆̆ı için bugün tedavide yalnızca 3 bileşik, glisirizin, kurkumin ve kalanolit A umut vaad etmektedir.

Klinik çalışması tamamlanmış veya halen devam etmekte olan ve umut verici sonuçlar elde edilmiş olan, glisirizin, kurkumin ve kalanolit A adlı bileşiklere ait klinik çalışmalar sonucunda elde edilen sonuçlar şu şekildedir:

\section{Glisirizin:}

Glisirizin, HIV replikasyonunu ve Sinsitiya formasyon oluşumunu in vitro ortamda inhibe etmektedir. Asemptomatik dönemde glisirizin ile tedaviye başlanan hastalarda, asemptomatik dönem 11 yıldan fazla bir süre boyunca, dirençli türler ve herhangi bir yan etki gözlenmeden sürdürülebilmektedir. (60), (61) 


\section{Kurkumin:}

Kurkumin bileşiği in vitro ortamda HIV replikasyonunu ve konakçı hücre genomuna virüs genomunun integrasyonunu sağlayan integraz enzimini inhibe eder. Test edilen HIV (+) hastalarda, bileşiğin HIV enfeksiyonunun etkilerini ortadan kaldırdığı tespit edilmiştir. (21), (22)

\section{Kalanolit A:}

(+)- Kalanolit A bileşiği virüsün RNA'sından DNA sentezlenmesini sağlayan, HIV Revers Transkriptaz enzimini in vitro ortamda inhibe etmektedir. Bileşiğin klinik çalışmaları halen devam etmektedir. Alınan sonuçlar olumlu yöndedir. Kalanolit A uygulanan HTV (+) hastalarda tedavi süresince viral yükün azaldı̆̆ı ve ilaca dirençli türlerin gözlenmediği belirlenmiştir. (5), (13)

Devam eden çalışmalarla klinikte kullanılabilecek bileşik sayısının artacağı da kesindir.

Sonuç olarak bitkisel kaynaklar, çağımızın en önemli hastalıklarından biri olan AİDS için umut verici kaynaklardan biridir.

\section{KAYNAKLAR:}

1. Öztürk,G., "AİDS ve Cevapsız Sorular", Bilim ve Teknik Dergisi, 26 (309), 567-573 (1993).

2. Öğün, S., Umay, A., "Dehşetini Hala Sürdüyor : AİDS", Bilim ve Tenik Dergisi, 20 (234), 3-7 (1987).

3. Ünal, S., ve ark., Güncel Bilgiler Işı̆̆ında HIV/AIDS, Bilimsel Tıp Yayınevi, Ankara, p.5-86, 149-198, 275-285 (1998)

4. Vlietinck, A.J., Bruyne, T., Apers, S., Pieters, L.A., "Plant-Derived Leading Compounds for Chemotherapy of Human Immunodeficiency Virüs (HIV) Infection", Planla Med., 64, 97-109 (1998).

5. Nash, R.J., Fellows, L.E., Dring, J.V., Stirton, C.H., Carter, D., Hegarty, M.P., Bell, E.A., "Castanospermine in Alexa species", Phytochemistry, 27 (5), 1403-1404 (1988).

6. Beutler, J.A., Cardellina, J.H., McMahon, J.B., Boyd, M.R., "Anti-HIV and Cytotoxic Alkaloids from Buchenavia capitata", J. Nat. Prod., 55, 207-213 (1992). 
7. Tan, G.T., Pezzuto, J.M., Kinghorn, A.D., Hughes, S.H., "Evaluation of Natural Products as Inhibitors of Human Immunodeficiency Virus Type-1 (HIV-1) Reverse Transcriptase", J. Nat.Prod, 54, 143-154 (1991).

8. McCormick, J.L., McKee, T.C., Cardellina, J.H., Boyd, M.R., "HIV Inhibitory Natural Products. 26. Quinoline Alkaloids from Euodia roxburghiana."', J. Nat. Prod., 59, 469471(1996).

9. Xu, Z., Chang, F., Wang, H., Kashiwada,Y., McPhail, A.T., Bastow, K.F., Tachibana, Y., Cosentino, M., Lee, K., "Anti-HIV Agents $45^{1}$ and Antitumor Agents 205. ${ }^{2}$ Two New Sesquiterpenes, Leitneridanins A and B, and the Cytotoxic and Anti-HIV Principles from Leitneriafloridana", J. Nat. Prod.T., 63, 1712-1715 (2000).

10. Kite, G.C., Horn, J.M., Romeo, J.T., Fellows, L.E., Lees, D.C., Scofields, A.M., Smith, N.G., "a-Homonojiricmycin and 2,5-Dihydroxymethyl-3,4-Dihydroxypyrrolidine: Alkaloidal Glycosidase Inhibitors in the Moth Urania fulgens", Phytochem., 29, 103-105 (1990)

11. Ma, C, Nakamura, N., Miyashiro, H., Hattori, M., Komatsu, K., Kawahata, T., Otake, T., "Screening of Chinese and Mongolian Herbal Drugs for Anti-human Immunodeficiency Virus Type 1 (HIV-1) Activity", Phytotherapy Research, 16, 186-189 (2002).

12. Yang, S.S., Cragg, G.M., Newman, D.J., Bader, J.P., "Natural Product-Based Anti-HIV Drug Discovery and Development Facilitated by the NCI Developmental Therapeutics Program", /. Nat. Prod., 64, 265-277 (2001).

13. Duan, H., Takaishi, Y., Imakura, Y., Jia, Y., Li, D., Cosentino, L.M., Lee, K., "Sesquiterpene Alkaloids from Tripterygium hypoglaucum and Tripterygium wilfordii: A New Class of Potent Anti-HIV Agents", J. Nat. Prod., 63, 357-361 (2000).

14. Otake, T., Mori, H., Morimoto, M., Ueba, N., Sutardjo, S., Kusumoto, T., Hattori, M., Namba, T., "Screening of Indonesian Plant Extracts for Anti-Human Immunodeficiency Virus-Type 1 (HIV-1) Activity", Phytother. Res., 9, 6-10 (1995).

15. Calabrese, C, Berman, S.H., Babish, J.G., Ma, X., Shinto, L., Dorr, M., Wells, K., Wenner, C.A., Standish, L.J., "A Phase I Trial of Andrographolide in HIV Positive Patients and Normal Volunteers", Phytother. Res., 14, 333-338 (2000). 
16. Alam, M.S., Quader, M.A., Rashid, M.A., "HIV-inhibitory diterpenoid from Anisomeles indica", Fitoterapia, 71, 574-576 (2000).

17. Ng, T.B., Huang, B., Fong, W.P., Yeung, H.W., "Anti-Human Immunodeficiency Virus (Anti-HIV) Natural Products with Special Emphasis on HIV Reverse Transcriptase Inhibitors", Life Sciences, 61 (10), 933-949 (1997).

18. Chen, K., Shi, Q., Fujioka, T., Zhang, D., Hu, C, Jin, J., Kilkuskie, R.E., Lee, K., Anti-AIDS Agents, 4. Tripterifordin, A Novel Anti-HIV Principle from Tripterygium wilfordii: Isolation and Structural Elucidation", J. Nat. Prod.T., 55, 88-92 (1992).

19. Kashiwada, Y., Nishizawa, M., Yamagishi, T., Tanaka, T., Nonaka, G., Cosentino, L.M., Sinider, J.V., Lee, K., "Anti-AIDS Agents, 18. ${ }^{1}$ Sodium and Potassium Salts of Caffeic Acid Tetramers from Arnebia euchroma as Anti-HIV Agents", J. Nat. Prod., 58, 392-400 (1995).

20. Lim, Y.A., Kojima, S., Nakamura, N., Miyashiro, H., Fushimi, H., Komatsu, K., Hattori, M., Shimotohno, K., Gupta, M.P., Correa, M., "Inhibitory Effects of Cordia spinescens Extracts and Their Constituents on Reverse Transcriptase and Protease from Human Immmunodeficiency Virus", Phytotherapy Research, 11, 490-495 (1997).

21. Roth, G.N., Chandra, A., Nair, M.G., "Novel Bioactivities of Curcuma longa Constituents", /. Nat. Prod., 61, 542-545 (1998).

22. Murray, M., Pizzorno, J., Encyclopedia of Natural Medicine, Prima Publishing, Rocklin, California, p. 199-209 (1998)

23. Kim, H.J., Woo, E.R., Shin, C.G., Park, H., "A New Flavonol Gallate Ester from Acer okamotoanum and Its Inhibitory Activity Against Human Immunodeficiency Virus-1 (HIV-1) Integrase", /. Nat. Prod., 61, 145-148 (1998).

24. Murga, R., Sanz, T.S., Beltran, S., Cabezas, J.L., "Solubility of Some Phenolic Compounds Contained in Grape Seeds, in Supercritical Carbon Dioxide", Journal of Supercritical Fluids, 23, 113-121 (2002).

25. Abe, I., Seki, T., Noguehi, H., Kashiwada, Y., "Galloyl Esters from Rhubarb are Potent Inhibitors of Squalene Epoxidase, a Key Enzyme in Cholesterol Biosynthesis", Planta Med., 66, 753-756 (2000). 
26. Ono, K., Sawada, T., Murata, Y., Saito, E., Iwasaki, A., Arakawa, Y., Kurokawa, K., Hashimoto, Y., "Pentagalloylglucose, an Antisecretory Component of Paeoniae radix, Inhibits Gastric H*, K+-ATPase", Clinica Chimica Acta, 290, 159-167 (200).

27. Lim, Y.A., Mei, M.C., Kusumoto, I.T., Miyashiro, H., Hattori, M., Gupta, M.P, Correa, M., "HFV-1 Reverse Transcriptase Inhibitory Principles from Chamaesyce Hyssopifolia", Phytotherapy Research, 11, 22-27 (1997).

28. Hu, C., Chen, K., Shi, Q., Kilkuskie, R.E., Cheng, Y., Lee, K., "Anti-AIDS Agents 10.' Acacetin-7-O-P-D-Galactopyranoside, an Anti-HIV Principle from Chrysanthemum morifolium and a Structure-Activity Correlation with Some Related Flavaonids", /. Nat.Prod., 57, 42-51 (1994).

29. McKee, T.C., Bokesch, H.R., McCormick, J.L., Rashid, M.A., Spielvogel, D., Gustafson, K.R., Alavanja, M.M., Cardellina, J.H., Boyd, M.R., "Isolation and Characterization of New Anti-HIV and Cytotoxic Leads from Plants, Marine, and Microbial Organisms", /. Nat. Prod., 60, 431-438 (1997).

30. Chen, S., Wan, M., Loh, B., "Active Constituents Against HIV-1 Protease from Garcinia mangostana", PlantaMed., 62, 381-382 (1996).

31. Lin, Y., Anderson, H., Flavin, M.T., Pai,Y.S., Mata-Greenwood, E., Pengsuparp, T., Pezzuto, J.M., Schinazi, R.F., Hughes, S.H., Chen, F., "In vitro Anti-HIV Activity of Biflavonoids Isolated from Rhus succedanea and Garcinia multiflora", J. Nat. Prod., 60, 884-888 (1997).

32. Groweiss, A., Cardellina, J.H., Boyd, M.R., "HIV-Inhibitory Prenylated Xanthones and Flavones from Madura tinctoria", J. Nat. Prod, 63, 1537-1539 (2000).

33. Meragelman, K.M., McKee, T.C., Boyd, M.R., "Anti-HIV Prenylated Flavonoids from Monotes africanus", J. Nat. Prod., 64, 546-548 (2001).

34. Wan, M., Bloor, S., Foo, L., Loh, B., "Screening of New Zealand Plant Extracts for Inhibitory Activity Against HIV-1 Protease", Phytotherapy Reserch, 10, 589-595 (1996).

35. Dellus, V., Mila, I., Scalbert, A., Menard, C, Michon, V., Penhoat, C.L., "Douglas-Fir Polyphenols and Hearwood Formation", Phytochem., 45, 1573-1578 (1997). 
36. Wang, J., Hou, C, Liu, Y., Lin, L., Gil, R.R., Cordell, G.A., "Svvertifrantheside, an HIV-Reverse Transcriptase Inhibitor and the First Flavone-Xanthone Dimer from Swertia franchetiana", J. Nat. Prod., 57, 211-217 (1994).

37. Piacente, S., Pizza, C., Tommasi, N., Mahmood, N., "Constituents of Ardisiajaponica and Their in vitro Anti-HIV Activity", J. Nat. Prod., 59, 565-569 (1996).

38. Dharmaratne, H.R.W., Wanigasekera, W.M.A.P., Mata-Greenwood, E., Pezzuto, J.M., "Inhibition of Human Immunodeficiency Virüs Type 1 Reverse Transcriptase Activity by Cordatolides Isolated from Calophyllum cordato-oblongum", Planta Med., 64, 460-461 (1998).

39. Patil, A.D., Freyer, A.J., Eggleston, D.S., Haltiwanger, R.C., Bean, M.F., Taylor, P.B., Caranfa, M.J., Breen, A.L., Bertus, H.R., Johnson, R.K., Hertzberg, R.P.,Westley, J.W., "The Inophyllums, Novel Inhibitors of HIV-1 Reverse Transcriptase Isolated from the Malaysian Tree, Calophyllum inophyllum Linn", Journal of Medicinal Chemistry, 36, 4131-4138(1993)

40. Pengsuparp, T., Şerit, M., Hughes, S.H., Soejarto, D.D., Pezzuto, J.M., "Specific Inhibition of Human Immunodeficiency Virüs Type 1 Reverse Transcriptase Mediated by Soulattrolide, a Coumarin Isolated from the Latex of Calophyllum teysmannii", $J$. Nat.Prod, 59, 839-842 (1996).

41. Gonzalez, M.J., Nascimento, M.S.J., Cidade, H.M., Pinto, M.M.M., Kijjoa, A., Anantachoke, C., Silva, A.M.S., Herz, W., "Immunomodulatory Activity of Xanthones from Calophyllum teysmannii var. inuphylloide", Planta Med., 65, 368-371 (1999).

42. Matthee, G., Wright, A.D., König, G.M., "HIV Reverse Transcriptase Inhibitors of Natural Origin", Planta Med., 65, 493-506 (1999).

43. Charlton, J.L., "Antiviral Activity of Lignans", /. Nat. Prod., 61, 1447-1451 (1998).

44. Chen, D., Zhang, S., Chen, K., Zhou, B., Wang, P., Cosentino, L.M., Lee, K., "Two New Lignans, Interiotherins A and B, as Anti-HIV Principles from Kadsura interior", $J$. Nat. Prod., 59, 1066-1068 (1996).

45. Hoang, V.D., Tan,G.T., Zhang, H.J., Tamez, P.A., Hung, N.V., Cuong, N.M., Soejarto, D.D., Fong, H.H.S., Pezzuto, J.M., "Natural anti-HIV agents-part I: (+)demethoxyepiexcelsin and verticillatol from Litsea verticillatd", Phytochemistry, 59 (3), 325-329 (2002). 
46. Valsaraj, R., Pushpangadan, P., Smitt, U.W., Adsersen, A., Christensen, S.B., Sittie, A., Nyman, U., Nielsen, C, Olsen, C.E., "New Anti-HIV-1, Antimalarial, and Antifungal Compounds from Terminalia bellerica", J. Nat. Prod., 60, 739-742 (1997).

47. Charan, R.D., Munro, M.H.G., O'Keefe, B., Sowder, R.C., McKee, T.C., Currens, M.J., Pannell, L.K., Boyd, M.R., "Isolation and Characterization of Myrianthus holstii Lectin, a Potent HIV-1 Inhibitory Protein from the Plant Myrianthus holstii", J. Nat. Prod., 63, 1170-1174(2000).

48. Bokesch, H.R., Pannell, L.K., Cochran, P.K., Sowder, R.C., McKee, T.C., Boyd, M. R., "A Novel Anti-HIV Macrocyclic Peptide from Palicourea condensata", J. Nat. Prod., 64, 249-250 (2001).

49. Saul, F.A., Rovira, P., Boulot, G., Damme, E.V., Peumans, W.J., Truffa-Bachi, P., Bentley, G.A., "Crystal Structure of Urtica dioica Agglutinin, A Superantigen Presented by MHC Molecules of Class I and II", Research Arcticle, 8, 593-603 (2000).

50. Kahlon, J B., Kemp, M C., Carpenter, R H., McAnalley, B H., McDaniel, H R., Shannon, W M., "Inhibition of AİDS Virüs Replication by Acemannan in vitro", Molecular Biotherapy, 3 (3), 127-135 (1991).

51. Lee, J., Hayashi, K., Hayashi, T., Sankawa, U., Maeda, M., "Antiviral Activities Against HSV-1, HCMV, and HIV-1 of Rhamnan Sulfate from Monostroma latissimum", Planta Med., 65, 439-441 (1999).

52. Haslin, C., Lahaye, M., Pellegrini, M., Chermann, J.C., "in vitro Anti-HIV Activity of Sulfated Cell-Wall Polysaccharides from Gametic, Carposporic and Tetrasporic Stages of the Mediterranean Red Alga Asparagopsis armata", Planta Med., 67, 301-305 (2001).

53. Hayashi, K., Hamada, J., Hayashi, T., "A Screening Strategy for Selection of Anti-HSV -1 and Anti-HIV Extracts from Algae", Phytotherapy Research, 10, 233-237 (1996).

54. Lau, A.F., Siedlecki, J., Anleitner, J., Patterson, G.M.L., Çaplan, F.R., Moore, R.E., "Inhibition of Reverse Transcriptase Activity by Extracts of Cultured Blue-Green Algae (Cyanophyta)", Planta Med., 59, 148-151 (1993).

55. Beress, A., Wassermann, O., Bruhn, T., Beress, L., Kraiselburd, E.N., Gonzalez, L.V., Motta, G.E., Chavez, P.L, "A New Procedure for the Isolation of Anti-HIV Compounds (Polysaccharides and Polyphenols) from the Marine Alga Fucus vesiculosus", J. Nat. Prod, 56, 478-488 (1993). 
56. Reshef, V., Mizrachi, E., Maretzki, T., Silberstein, C, Loya, S., Hizi, A., Carmeli, S., "New Acylated Sulfoglycolipids and Digalactolipids and Related Known Glycolipids from Cyanobacteria with a Potential to Inhibit the Reverse Transcriptase of HIV-1", /. Nat. Prod., 60, 1251-1260(1997).

57. Loya, S., Reshef, V., Mizrachi, E., Silberstein, C, Rachamim, Y., Carmali, S., Hizi, A., "The Inhibition of the Reverse Transcriptase of HIV-1 by the Natural Sulfoglycolipids from Cyanobacteria: Contribution of Different Moieties to Their High Potency", J. Nat. Prod., 61, 891-895(1998).

58. Kusumoto, I.T., Nakabayashi, T., Kida, H., Miyashiro, H., Hattori, M., Namba, T., Shimotohno, K., "Screening of Various Plant Extracts Used in Ayurvedic Medicine for Inhibitory Effects on Human Immunodeficiency Virüs Type 1 (HIV-1) Protease", Phytotherapy Research, 9, 180-184 (1995).

59. Kim, H.J., Lee, J.S., Woo, E., Kim, M.K., Yang, B.S., Yu, Y.G., Park, H., Lee, Y.S., "Isolation of Virus-Cell Fusion Inhibitory Components from Eugenia caryophyllata", Planta Med., 67, 277-279 (2001).

60. Hussein, G., Miyashiro, H., Nakamura, N., Hattori, M., Kaveahata, T., Otake, T., Kakiuchi, N., Shimotohno, K., "Inhibitory Effects of Sudanese Plant Extracts on HIV-1 Replication and HIV-1 Protease", Phytotherapy Research, 13, 31-36 (1999).

61. Yoshida, T., Ito, H., Hatano, T., Nakanishi, T., inada, A., Murata, H., Inatomi, Y., Matsuura, N., Ono, K., Nakane, H., Noda, M., Lang, F.A., Murata, J., "New Hydrolyzable Tannins, Shephagenins A and B. From Sepherdia argentea as HIV-1 Reverse Transcriptase Inhibitors", Chem.Pharm. Bull, 44, 1436-1439 (1996)

62. Matsuse, I.T., Nakabayashi, T., Lim, Y.A., Hussein, G.M.E., Miyashiro, H., Kakiuchi, N., Hattori, M., Stardjo, S., Shimotohno, K., "A Human Immunodeficiency Virüs Protease Inhibitory Substance from Svvietenia mahagoni", Phytotherapy Research, 11, 433-436 (1997).

63. Nishizawa, M., Yamagishi, T., Dutschman, G.E., Parker, W.B., Bodner, AJ., Kilkuskie, R.E., Cheng, Y., Lee, K., "Anti-AIDS Agents, 1. ${ }^{1}$ Isolation and Characterization of Four New tetragalloylquinic Acids as a New Class of HIV Reverse Transcriptase Inhibitors fromTannic Acid", /. Nat. Prod., 52, 762-768 (1989). 
64. Yang, X., ZhaoJ., Cui, Y., Liu, X., Ma, C, Hattori, M., Zhang, L., "Anti-HIV-1 Protease Triterpenoid Saponins from the Seeds of Aesculus chinensis", J. Nat. Prod., 62, 1510-1513(1999).

65. Xu, H., Zeng, F., Wan, M., Sim, K., "Anti-HIV Triterpene Acids from Geum japonicum", J. Nat. Prod., 59, 643-645 (1996).

66. Konoshima, T., Yasuda, I., Kashiwada, Y., Cosentino, L.M., Lee, K., "Anti-AIDS Agents, 21..$^{1}$ Triterpenoid Saponins as Anti-HIV Principles from Fruits of Gleditsia japonica and Gymnocladus chinensis, and A Structure-Activity Correlation", J. Nat. Prod., 58, 1372-1377 (1995).

67. Mori, K., Sakai, H., Suzuki, S., Akutsu, Y., Ishikawa, M., Imaizumi, M., Tada, K., Aihara, M., Sawada, Y., Yokoyama, M., "Preliminary Evidence for Inhibitory Effect of Glycyrrhizin on HIV Replication in Patients with AİDS", The Tohoku Journal of Experimental Medicine, 162 (2), 183-193 (1990).

68. Ikegami, N., Kinoshita, S., Kanesaki, T., Uno, K., Akatani, K., Kishida, T., "Evaluation of Long-term Treatment with Glycyrrhizin and of Combination Therapy with Glycyrrhizin and AZT or DDI on HIV-1 Carriers", Antiviral Research, 30 (1), A33 (1996).

69. Hayashi, K., Hayashi,H., Hiraoka,N., Ikeshiro, Y., "Inhibitory Activity of Soyasaponin II on Virüs Replication in vitro", Planta Med., 63, 102-105 (1997).

70. Kashiwada, Y., Wang, H., Nagao, T., Kitanaka, S., Yasuda, I., Fujioka, T., Yamagishi, T., Cosentino, L.M., Kozuka, M., Okabe, H., Ikeshiro, Y., Hu, C, Yeh, E., Lee, K., "Anti-AIDS Agents. 30. Anti-HIV Activity of Oleanolic Acid, Pomolic Acid, and Structurally Related Triterpenoids"" J. Nat. Prod., 61, 1090-1095 (1998).

71. Kashiwada, Y., Nagao, T., Hashimoto, A., Ikeshiro, Y., Okabe, H., Cosentino, L.M., Lee, K., "Anti-AIDS Agents 38. Anti-HIV Activity of 3-O-Acyl Ursolic Acid Derivatives",, /. Nat. Prod., 63, 1619-1622 (2000).

72. Chen, D., Zhang, S., Wang, H., Zhang, S., Sun, Q., Cosentino, L.M., Lee, K., "Novel Anti-HIV Lancilactone $\mathrm{C}$ and Related Triterpenes from Kadsura lancilimba"n, J. Nat. Prod., 62, 94-97 (1999). 
73. Hasegawa, H., Matsumiya, S., Uchiyama, M., Kurokavva, T., Inouye,Y., Kasai, R., Ishibashi, S., Yamasaki, K., "Inhibitory Effect of Some Triterpenoid Saponins on Glucose Transport in Tumor Cells and Its Application to in vitro Cytotoxic and Antiviral Activities", Planta Med., 60, 240-243 (1994).

74. L., H., Sun, N., Kashiwada, Y., Sun, L., Snider, J.V., Cosentino, L.M., Lee, K., "AntiAIDS Agents, 9.' Suberosol, A New $\mathrm{C}_{31}$ Lanostane-Type Triterpene and Anti-HIV Principle from Polyalthia suberosa", J. Nat. Prod., 56, 1130-1133 (1993).

75. Ito, J., Chang, F.R., Wang, H., Park, Y.K., Ikegaki, M., Kilgore, N., Lee, K.H., "AntiAIDS Agents. 48. Anti-HIV Activity of Moronic Acdi Derivatives and the New Melliferone- Related Triterpenoid Isolated from Brazilian Propolis", /. Nat. Prod., 64, 1278-1281 (2001)

76. Sun, H., Qui,S., Lin, L., Wang, Z., Lin, Z., Pengsuparp, T., Pezzuto, J.M., Fong, H.H.S., Cordell, G.A., Farnsworth, N.R., "Nigranoic Acid, a Triterpenoid from Schisandra sphaerandra That Inhibits HIV-1 Reverse Transcriptase", J. Nat. Prod., 59, 525-527 (1996).

77. Fujioka, T., Kashiwada, Y., Kilkuskie, R.E., Cosentino, L.M., Ballas, L.M., Jiang, J.B., Janzen, W.P., Chen, I., Lee, K., "Anti-AIDS Agents, İ1. ${ }^{1}$ Betulinic Acid and Platanic Acid as Anti-HIV Principles from Syzigium claviflorum, and the Anti-HIV acvitiy of Structurally Related Triterpenoids", /. Nat. Prod., 57, 243-247 (1994).

78. Chen, K., Shi, Q., Kashiwada, Y., Zhang, D., Hu, C, Jin, J., Nozaki, H., "Anti-AIDS Agents, 6 . Salaspermic Acid, an Anti-HIV Principle From Tripterygium wilfordii, and the Structure-Activity Correlation with its Related Compounds", J. Nat. Prod., 55, 340- 346 (1992).

79. Ma, C, Nakamura, N., Hattori, M., Kakuda, H., Qiao, J., Yu, H., "Inhibitory Effects on HIV-1 Protease of Constituents from the Wood of Xanthoceras sorbifolia", J. Nat. Prod., 63, 238-242(2000). 